\title{
Review Article \\ Cancer Stem Cells (CSCs) in Drug Resistance and their Therapeutic Implications in Cancer Treatment
}

\author{
Lan Thi Hanh Phi $(D$, Ita Novita Sari, Ying-Gui Yang, Sang-Hyun Lee, Nayoung Jun, \\ Kwang Seock Kim, Yun Kyung Lee $\mathbb{i}$, and Hyog Young Kwon $\mathbb{i}$ \\ Soonchunhyang Institute of Medi-bio Science (SIMS), Soonchunhyang University, Asan, Republic of Korea \\ Correspondence should be addressed to Yun Kyung Lee; yunklee@sch.ac.kr and Hyog Young Kwon; hykwon@sch.ac.kr
}

Received 28 September 2017; Accepted 11 January 2018; Published 28 February 2018

Academic Editor: Pratima Basak

Copyright ( $) 2018$ Lan Thi Hanh Phi et al. This is an open access article distributed under the Creative Commons Attribution License, which permits unrestricted use, distribution, and reproduction in any medium, provided the original work is properly cited.

\begin{abstract}
Cancer stem cells (CSCs), also known as tumor-initiating cells (TICs), are suggested to be responsible for drug resistance and cancer relapse due in part to their ability to self-renew themselves and differentiate into heterogeneous lineages of cancer cells. Thus, it is important to understand the characteristics and mechanisms by which CSCs display resistance to therapeutic agents. In this review, we highlight the key features and mechanisms that regulate CSC function in drug resistance as well as recent breakthroughs of therapeutic approaches for targeting CSCs. This promises new insights of CSCs in drug resistance and provides better therapeutic rationales to accompany novel anticancer therapeutics.
\end{abstract}

\section{Introduction}

Cancer is one of the leading causes of morbidity and mortality worldwide with about $20 \%$ of all deaths in developed countries [1]. From preclinical and clinical cancer studies, various new diagnostic and treatment options for cancer patients provide notable progresses in cancer treatment and prevention [2]. Cancer heterogeneity is one of the reasons contributing to the treatment failure and disease progression. Among several cancer treatments, the main treatments that are commonly used to treat patients are surgery, radiotherapy, and chemotherapy. Surgery can successfully remove cancer from the body, while combining radiotherapy with chemotherapy can effectively give better results for treating many types of cancer [3]. Recent chemotherapeutic agents are successful against primary tumor lesions and its residue after surgery or radiotherapy [4]. However, chemotherapy induces tumor heterogeneity derived from both normal and cancer cells and the heterogeneity within tumors, in turn, results in reducing effects of chemotherapy; contributing to the treatment failure and disease progression $[5,6]$. Chemoresistance is a major problem in the treatment of cancer patients, as cancer cells become resistant to chemical substances used in treatment, which consequently limits the efficiency of chemo agents [7]. It is also often associated with tumors turning into more aggressive form and/or metastatic type [8-11].

Accumulating evidences suggest that cancer stem cell (CSC) population, a subgroup of cancer cells, is responsible for the chemoresistance and cancer relapse, as it has ability to self-renew and to differentiate into the heterogeneous lineages of cancer cells in response to chemotherapeutic agents [12-14]. CSCs are also able to induce cell cycle arrest (quiescent state) that support their ability to become resistant to chemo- and radiotherapy [15-20]. Common chemotherapeutic agents target the proliferating cells to lead their apoptosis, as mentioned previously. Although successful cancer therapy abolishes the bulk of proliferating tumor cells, a subset of remaining CSCs can survive and promote cancer relapse due to their ability to establish higher invasiveness and chemoresistance [21,22]. Understanding the features of CSCs is important to establish the foundation for new era in treatment of cancer. In this review, we address the detailed mechanisms by which CSCs display the resistance to chemo- and radiotherapy and their implication for clinical trials. 


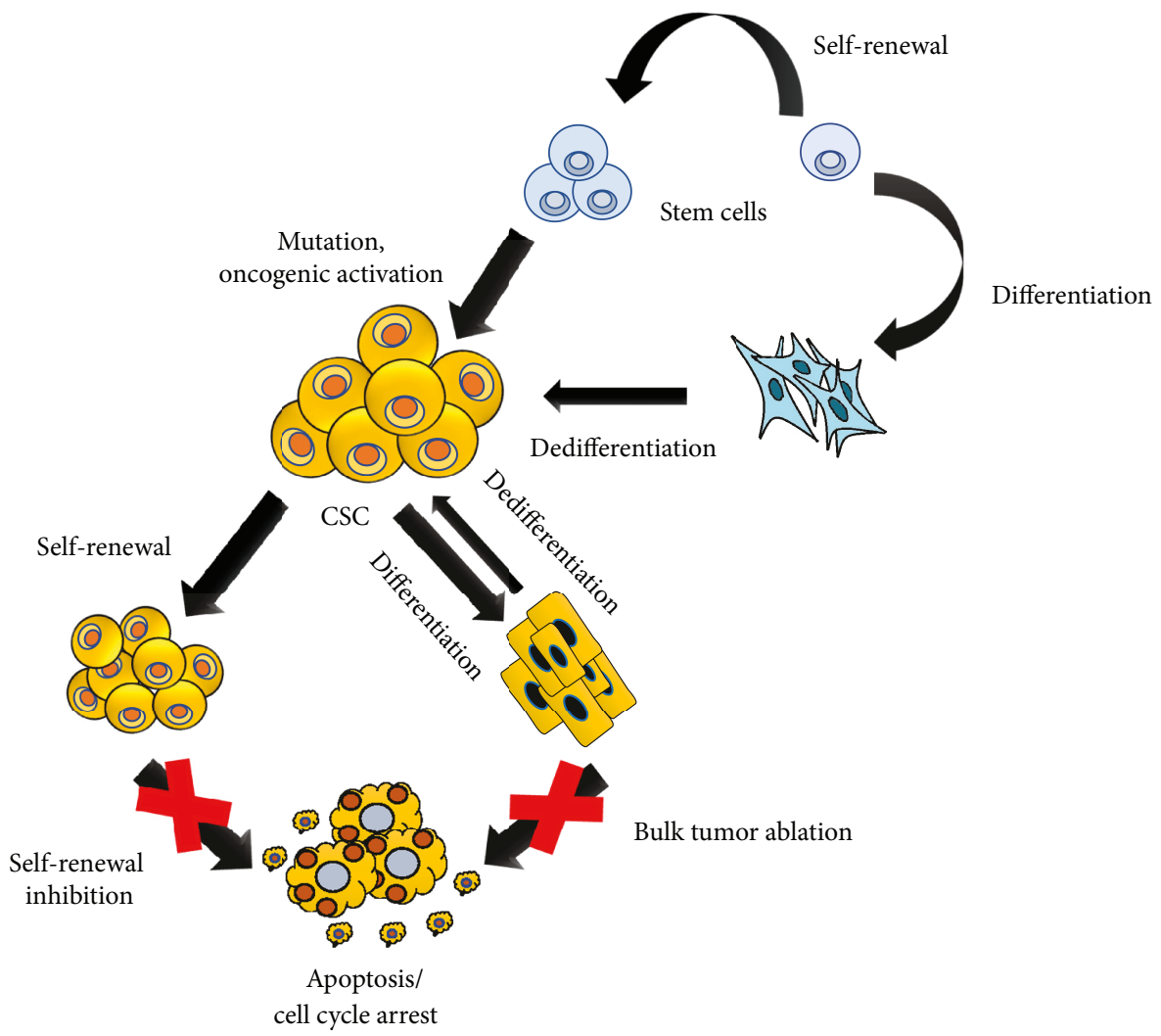

FIGURE 1: The origin of CSCs and combinational therapy of CSC targeting and bulk tumor ablation. CSCs could possibly have originated from either stem cells with mutation/oncogenic transformation, progenitors that have undergone mutation, or from differentiated cells or cancer cells that obtained stem-like properties by dedifferentiation. Thus, because of the plasticity of CSCs, it is suggested that combinational therapy of CSC targeting and bulk tumor ablation may have better therapeutic effects to improve the clinical outcomes of cancer patients.

\section{The Origin and Surface Markers of Cancer Stem Cells (CSCs)}

Cancer stem cells (CSCs), also known as tumor-initiating cells (TICs), have been intensively studied in the past decade, focusing on the possible source, origin, cellular markers, mechanism study, and development of therapeutic strategy targeting their pathway $[23,24]$. The first convincing evidence of CSCs was reported by Bonnet and Dick in 1997 by the identification of a subpopulation of leukemia cells expressing surface marker CD34, but not CD38. CD $34^{+} /$ CD38 ${ }^{-}$subpopulation was capable of initiating tumor growth in the NOD/SCID recipient mice after transplantation [25]. In addition to blood cancer, CSCs have been identified in several kinds of solid tumor $[21,26]$. The first evidence of the presence of CSCs in solid cancer in vivo was found and identified as $\mathrm{CD} 44^{+} \mathrm{CD} 24^{-/ \text {low }^{2}}$ Lineage ${ }^{-}$cells in immunocompromised mice after transplanting human breast cancer cells in 2003 [27] even though it has been indicated in vitro in 2002 by the discovery of clonogenic (sphere-forming) cells isolated from human brain gliomas [28]. Over time, CSC population was also identified from several other solid cancers including melanoma, brain, lung, liver, pancreas, colon, breast cancer, as well as ovarian cancer [27, 29-35].

Although CSC model explains the heterogeneity of cancers in terms of hierarchical structure and progression mode, the origins of CSCs are currently unclear and controversial [36, 37]. Accumulating hypotheses suggest that depending on the tumor type, CSCs might be derived from either adult stem cells, adult progenitor cells that have undergone mutation, or from differentiated cells/cancer cells that obtained stem-like properties through dedifferentiation $[25,38-50]$. Because of the plasticity of CSCs, it has been suggested that the combinational therapy of targeting CSC pathways and conventional chemotherapeutics might have better therapeutic effect, which will be explained later in detail (Figure 1). Early studies in AML demonstrated that normal primitive cells, but not committed progenitor cells, are targets for leukemic transformation [25]. Similarly, it has been indicated that deletion of Apc in $\operatorname{Lgr}^{+}$(leucine-rich-repeat containing G-protein coupled receptor 5) long-lived intestinal stem cells, rather than short-lived transit-amplifying cells, could lead to their transformation, showing that stem cells are the cells-of-origin in intestinal cancer [42]. Moreover, long-term culture can also induce telomerase-transduced adult human mesenchymal stem cells (hMSCs) to undergo spontaneous transformation, showing that these cells are also the origin of CSCs $[43,44]$. Interestingly, CSCs originate from the transformation of not only their tissue-specific stem cells but also other tissue stem cells. For instance, bone marrow-derived cells (BMDCs) may be an essential 
TABLE 1: Cancer stem cell markers in human.

\begin{tabular}{lcc}
\hline Tumor type & Cancer stem cell markers & Reference \\
\hline Lung cancer & $\mathrm{CD} 133^{+}, \mathrm{CD} 44^{+}, \mathrm{ABCG}, \mathrm{ALDH}, \mathrm{CD} 87^{+}, \mathrm{SP}, \mathrm{CD} 90^{+}$ & {$[215-217]$} \\
Colon cancer & $\mathrm{CD} 133^{+}, \mathrm{CD} 44^{+}, \mathrm{CD} 24^{+}, \mathrm{CD} 166^{+}, \mathrm{EpCAM}{ }^{+}, \mathrm{ALDH}, \mathrm{ESA}$ & {$[218,219]$} \\
Liver cancer & $\mathrm{CD} 133^{+}, \mathrm{CD} 44^{+}, \mathrm{CD} 49 \mathrm{f}^{+}, \mathrm{CD} 90^{+}, \mathrm{ALDH}, \mathrm{ABCG} 2, \mathrm{CD} 24^{+}, \mathrm{ESA}$ & {$[51,219]$} \\
Breast cancer & $\mathrm{CD} 133^{+}, \mathrm{CD} 44^{+}, \mathrm{CD} 24^{-}, \mathrm{EpCAM}{ }^{+}, \mathrm{ALDH}-1$ & {$[51,218]$} \\
Gastric cancer & $\mathrm{CD} 133^{+}, \mathrm{CD} 44^{+}, \mathrm{CD} 24^{+}$ & {$[215,220-222]$} \\
Leukemia (AML) & $\mathrm{CD} 34^{+}, \mathrm{CD} 38^{-}, \mathrm{CD} 123^{+}$ & {$[216,218,223]$} \\
Prostate cancer & $\mathrm{CD} 133^{+}, \mathrm{CD} 44^{+}, \alpha 2 \beta 1, \mathrm{ABCG} 2, \mathrm{ALDH}$ & {$[51,215,223]$} \\
Pancreatic cancer & $\mathrm{CD} 133^{+}, \mathrm{CD} 44^{+}, \mathrm{CD} 24^{+}, \mathrm{ABCG} 2, \mathrm{ALDH}, \mathrm{EpCAM}{ }^{+}, \mathrm{ESA}$ & {$[195,215,218]$} \\
Melanoma & $\mathrm{ABCB} 5^{+}, \mathrm{CD} 20^{+}$ & {$[51,217]$} \\
Head and neck cancer & $\mathrm{SSEA}-1^{+}, \mathrm{CD} 44^{+}, \mathrm{CD} 133^{+}$ & {$[224-226]$} \\
\hline
\end{tabular}

source of many tumor types, such as gastric cancer, neural tumors, and even teratoma [45].

CSCs also have been demonstrated to be generated by dedifferentiation from progenitor cells or differentiated cells which have acquired "stemness" properties as a result of the accumulation of extra genetic or epigenetic abnormalities [46]. For example, BCR-ABL fusion protein is present in hematopoietic stem cell- (HSC-) like CML cells but granulocyte-macrophage progenitors are found to be a candidate of the advanced-stage LSCs during blast crisis in blast-crisis CML by activating the self-renewal process via $\beta$-catenin pathway [47]. In addition, it has been shown that oncogenic Hh signaling can promote medulloblastoma from either lineage-restricted granule cell progenitors or stem cells $[48,49]$. Besides, most differentiated cells in the CNS, including terminally differentiated neurons and astrocytes, can acquire defined genetic alterations to dedifferentiate into NSC or progenitor state and consequently induce and maintain malignant gliomas [50].

Of note, CSCs can be identified by specific markers of normal stem cells which are commonly used for isolating CSCs from solid and hematological tumors [51]. Several cell surface markers have been verified to identify CSCenriched populations, such as CD133, CD24, CD44, EpCAM (epithelial cell adhesion molecule), THY1, ABCB5 (ATP-binding cassette B5), and CD200 [27, 32, 34, 52]. Additionally, certain intracellular proteins also have been used as CSCs markers, such as aldehyde dehydrogenase 1 (ALDH1) which is used to characterize CSCs in many types of cancer such as leukemia, breast, colon, liver, lung, pancreas, and so forth $[12,53]$. The usage of cell surface markers as CSC markers might differ from each cancer types depending on their characteristics and phenotypes. The surface markers that are frequently used to isolate CSCs from each cancer types are listed in Table 1.

\section{The Mechanisms by Which CSCs Contribute to the Resistance against Chemotherapy and Cancer Relapse}

Recent studies suggest that CSCs are enriched after chemotherapy because a small subpopulation of cells remaining in tumor tissue, so-called CSCs, can survive and expand though most chemotherapeutic agents kill bulk of tumors [12-14]. For instance, preleukemic DNMT3Amut HSCs which can initiate clonal expansion as the first step in leukemogenesis and regenerate the entire hematopoietic hierarchy were found to survive and expand in the bone marrow remission after chemotherapy [54]. Similarly, exposure to therapeutic doses of temozolomide (TMZ), the most commonly used antiglioma chemotherapy, consistently expands the glioma stem cell (GSC) pool over time in both patient-derived and established glioma cell lines, which has been shown to be a result of phenotypic and functional interconversion between differentiated tumor cells and GSCs [55]. Moreover, the humanized VEGF antibody bevacizumab reduces glioblastoma multiforme (GBM) tumor growth but followed by tumor recurrence, possibly due to the ongoing autocrine signaling through the VEGF-VEGFR2-Neuropilin-1 (NRP1) axis, which is associated with the enrichment of active VEGFR2 GSC subset in human GBM cells [56]. The gefitinib-resistant subline HCC827-GR-highs established by high-concentration method also acquire both the EMT and stem cell-like features but do not show any EGFR-mutantspecific protein production or further increase in the number of either mutant allele or EGFR copy [57]. Therefore, by understanding the mechanisms and oncogenic drivers by which the CSCs escape the radio- and chemotherapy, we can develop more effective treatments that could improve the clinical outcomes of cancer patients. The mechanisms by which CSCs contribute to the chemoresistance including EMT, MDR, dormancy, tumor environment, and so forth are mentioned below in detail and summarized in Figure 2.

3.1. Epithelial Mesenchymal Transition (EMT). It has been indicated that epithelial mesenchymal transition (EMT) markers and stem cell markers are coexpressed in circulating tumor cells from patients with metastasis [58] and EMT induction or activation of EMT transcription factors (TFs) confers stem-like features in cancer cells [59]. In particular, normal and neoplastic human breast stem-like cells express similar markers with cells that have undergone EMT, and EMT induces the generation of relatively unlimited numbers of cancer stem cells from more differentiated neoplastic cells 


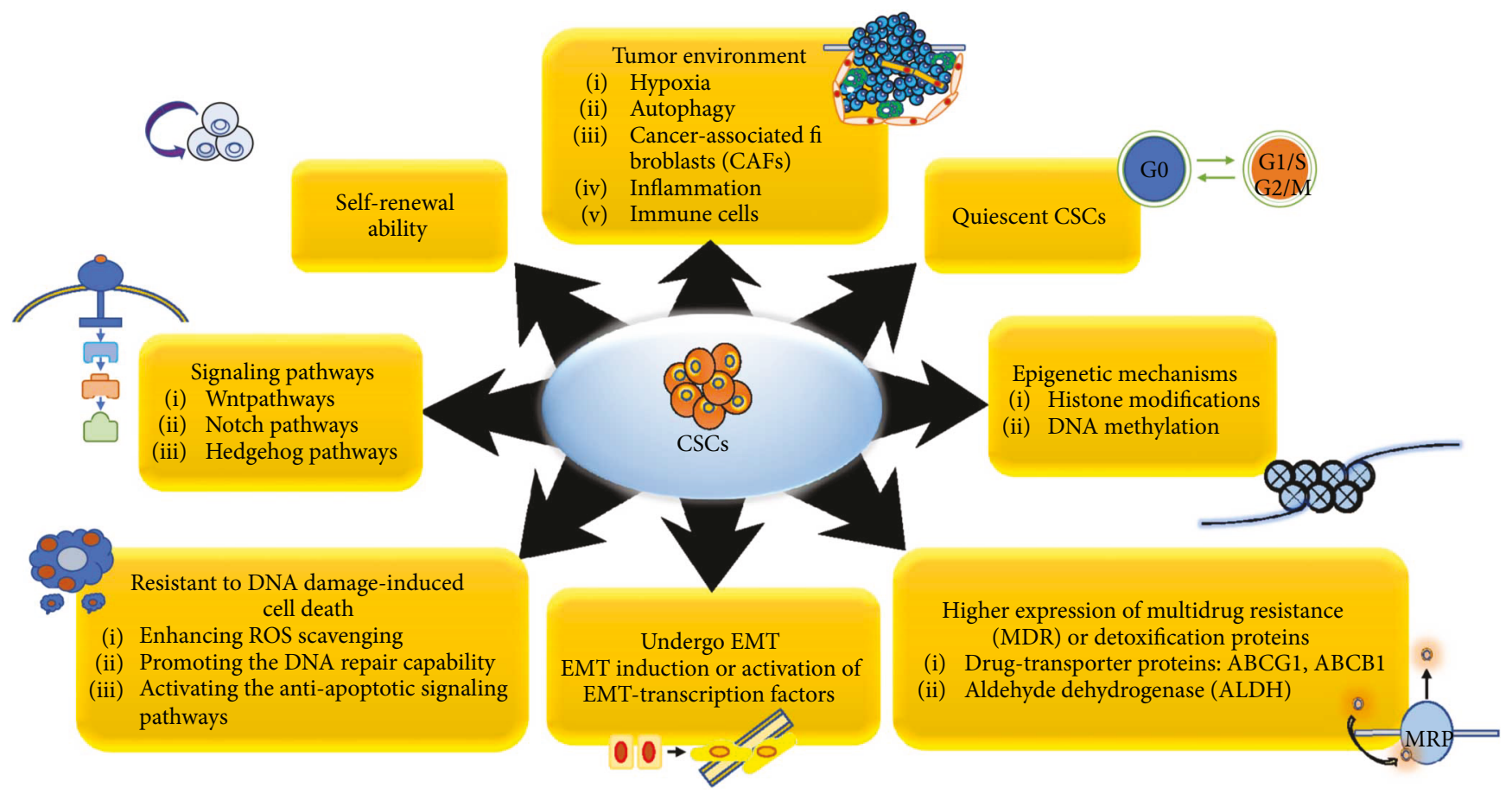

FIGURE 2: Key signaling pathways and modifications of CSCs contributing to the resistance against chemotherapeutics. In order to survive during and after therapy, CSCs display many responses including EMT, self-renewal, tumor environment, quiescence, epigenetic modification, MDR, and so forth. The mechanisms by which CSCs contribute to resistance against therapeutics are summarized.

[60]. Meanwhile, there is an association between EMT activation and drug resistance [61]. For instance, gefitinib-induced resistant lung cancer cells acquire EMT phenotype [62] through activation of Notch-1 signaling [63]. Moreover, enhanced invasive potential, tumorigenicity, and expression of EMT markers could be used to predict the resistance of anti-EGFR antibody cetuximab in the cells [64]. In parallel, compared with epithelial cell lines, the mesenchymal cells have increased expression of genes involved in metastasis and invasion and are significantly less susceptible to EGFR inhibition, including erlotinib, gefitinib, and cetuximab; at least partly via integrin-linked kinase (ILK) overexpression in mesenchymal cells [65]. Besides, EMT mediator S100A4 has been shown to involve in maintaining the stemness properties and tumorigenicity of CSCs in head and neck cancer [66]. Therefore, EMT induces the cancer cells to exhibit stem cell-like characteristics which promote cells to invade surrounding tissues and display therapeutic resistance [67]. Interestingly, ZEB1, a regulator of EMT, plays an important role in key features of cancer stem cells including the regulation of stemness and chemoresistance induction through transcriptional regulation of O-6-Methylguanine DNA Methyltransferase (MGMT) via miR-200c and cMYB in malignant glioma [68]. Apart from EMT, the high expression of stem cell markers such as Oct4, Nanog, Sox2, Musashi, and Lgr5 has been considered to confer chemoresistance as well [69-73].

3.2. High Levels of Multidrug Resistance (MDR) or Detoxification Proteins. Side population (SP) cells, which exhibit a cancer stem cell-like phenotype, are detected in a variety of different solid tumors such as retinoblastoma, neuroblastoma, gastrointestinal cancer, breast cancer, lung cancer, and glioblastoma; their high expression of drugtransporter proteins (including MDR1, ABCG2, and ABCB1) not only acts to exclude Hoechst dye but also expels cytotoxic drugs, leading to high resistance to chemotherapeutic agents with better cell survival and disease relapse [74-76]. Alisi et al. suggest that the overexpression of ABC protein is probably the most important protective mechanism for CSCs in response to chemotherapeutic agents [77]. Interestingly, it has been demonstrated that the PI3K/ Akt pathway specifically regulates ABCG2 activity via its localization to the plasma membrane, and loss of PTEN promotes the SP phenotype of human glioma cancer stem-like cells [78]. Moreover, the activity of aldehyde dehydrogenase (ALDH), a cytosolic enzyme that is responsible for the oxidation of intracellular aldehydes to protect cells from the potentially toxic effects of elevated levels of reactive oxygen species (ROS) [79], is high in both normal and patients' CD $34^{+} /$ CD $38^{-}$leukemic stem cells, and thus plays an important role in resistance to chemotherapy [80]. ALDH activity is a potential selective marker for cancer stem cells in many different types of cancer, such as breast cancer [53], bladder cancer [81], head and neck squamous cell carcinoma [82], lung cancer [83], and embryonal rhabdomyosarcoma [84]. Interestingly, cell culture model systems and clinical sample studies show that ALDH1A1-positive cancer stem cells promote significant resistance to both EGFR-TKI (gefitinib) and other anticancer chemotherapy drugs (cisplatin, etoposide, and fluorouracil) than ALDH1A1-negative cells in lung cancer [85]. In addition, high levels of ALDH1 expression predict 
a poor response or resistance to preoperative chemoradiotherapy in resectable esophageal cancer patients [86].

3.3. Dormancy of CSCs. It has been demonstrated that besides the intratumoral heterogeneity initiated by the evolution of genetically diverse subclones, there are also functionally distinct clones, which were found by tracking the progeny of single cells using lentivirus, within a genetic lineage in colorectal cancers [87]; accordingly, these diversity-generating processes within a genetic clone promote cells for higher survival potential, especially during stress such as chemotherapy. For example, chemotherapy can induce the tumor growth of previously relatively dormant or slowly proliferating lineages that still retain potent tumor propagation potential, leading to both cancer growth and drug resistance [87]. Similarly, in glioblastoma multiforme, there is also the existence of a relatively quiescent subset of endogenous tumor cells with characteristics similar to cancer stem cells responsible for maintaining the long-term tumor growth and therefore leading to recurrence via the production of transient populations of highly proliferative cells [17]. Concomitantly, chemotherapy-induced damages recruit the quiescent label-retaining pool of bladder CSCs during the gap periods between chemotherapy cycles into an unexpected cell division response to repopulate residual tumors, similar to wound repair mobilization of tissue resident stem cells [88].

3.4. Resistance to DNA Damage-Induced Cell Death. CSCs can be resistant to DNA damage-induced cell death through several ways. These include protection against oxidative DNA damage by enhanced ROS scavenging, promotion of the DNA repair capability through ATM and CHK1/CHK2 phosphorylation, or activation of the anti-apoptotic signaling pathways, such as PI3K/Akt, WNT/b-catenin, and Notch signaling pathways [24]. For instance, CD44, an adhesion molecule expressed in CSC, interacts with a glutamate-cystine transporter and controls the intracellular level of reduced glutathione (GSH); hence, the CSCs expressing a high level of CD44 showed an enhanced capacity for GSH synthesis, resulting in stronger defense against ROS [89]. Interestingly, similar to normal tissue stem cells, CSCs have lower ROS levels, which is associated with increased expression of free radical scavenging systems, leading to higher ROS defenses and radiotherapy resistance as well [90]. In addition, $\mathrm{CD} 44^{+} / \mathrm{CD} 24^{- \text {low }} \mathrm{CSC}$ subset in breast cancer is resistant to radiation via activation of ATM signaling but does not depend on alteration of nonhomologous end joining (NHEJ) DNA repair activity [91]. Similarly, CD133-expressing tumor cells isolated from both human glioma xenografts and primary patient glioblastoma specimens preferentially activate the DNA damage checkpoint in response to radiation and repair radiation-induced DNA damage more effectively than CD133-negative tumor cells [92]. Notch pathway also promotes the radioresistance of glioma stem cells as the Notch inhibition with gamma-secretase inhibitors (GSIs) induces the glioma stem cells to be more sensitive to radiation at clinically relevant doses due to the reduction of radiation-induced PI3K/Akt activation and upregulated levels of truncated apoptotic isoform of Mcl-1 (Mcl-1s) while not altering DNA damage response [93].

3.5. Tumor Environment. It has been shown that a distinct microenvironment of various cellular composition is important to protect and regulate normal stem cells. An equivalent microenvironment was also found in the CSCs in which CSCs was favorably supported within a histologic niche, so-called CSC microenvironment [94-96], containing connective stromal [97-101] and vascular tissues [102-106]. This environment expedites CSC divisional dynamics, allowing them to differentiate progenitor daughter cells as well as self-renew and maintain CSCs in the primitive developmental state. The cells within CSC microenvironment are capable of stimulating signaling pathways [58], such as Notch [102, 107, 108] and Wnt [109-111] which may facilitate CSCs to metastasize, evade anoikis, and alter divisional dynamics, achieving repopulation by symmetric division [109, 112-114].

3.5.1. Hypoxia. Hypoxia and HIF signaling pathway have been shown to contribute to the regulation and sustenance of CSCs and EMT phenotype such as cell migration, invasion, and angiogenesis [115], via the increased expression of VEGF, IL-6, and CSC signature genes such as Nanog, Oct4, and $\mathrm{EZH} 2$, in pancreatic cancer for example [116]. Therefore, hypoxia and HIF signaling pathway may also play a role in CSC resistance to therapy. In the hypoxic microenvironment, hypoxia and hypoxia-inducible factor HIF1- $\alpha$ signaling promote CML cell persistence mainly through the upregulation of hypoxia-inducible factor $1 \alpha$ (HIF1- $\alpha)$, independent of BCR-ABL1 kinase activity [117]. Similarly, hypoxia increases gefitinib-resistant lung CSCs in EGFR mutation-positive NSCLC by upregulating expression of insulin-like growth factor 1 (IGF1) through HIF1 $\alpha$ and activating IGF1 receptor (IGF1R) [118]. Interestingly, autophagy is upregulated in the pancreatic cancer in the microenvironmental condition of low oxygen and lack of nutrition, similar with the hypoxic tumor, and then promotes the clonogenic survival and migration of pancreatic CSC ${ }^{\text {high }}$ cells [119].

3.5.2. Cancer-Associated Fibroblasts (CAFs). It has been indicated that besides cell autonomous resistance of CSCs, chemotherapy preferentially targets non-CSCs by the stimulation of cancer-associated fibroblasts (CAFs) which creates a chemoresistant niche by increased secretion of specific cytokines and chemokines, including interleukin-17A (IL-17A), a CSC maintenance factor by promoting selfrenewal and invasion [120]. It has been shown previously that CSCs can differentiate into CAF-like cells (CAFLCs) and hence they are one of the key sources of CAFs which support the tumor maintenance and survival in the cancer niche [121]. CAFs are known to secrete many different growth factors, cytokines, and chemokines, including hepatocyte growth factor (HGF), which activates the MET receptors to protect the CSCs from apoptosis in response to the cetuximab monotherapy targeting the EGFR in metastatic colorectal cancer [122]. 
3.5.3. Inflammation. In addition, long-term treatment of breast cancer cells with trastuzumab specifically enriched CSCs which exhibit EMT phenotypes with higher levels of secreted cytokines IL-6 compared with parental cells; as a consequence, these cells develop trastuzumab resistance mediated by activation of an IL-6-mediated inflammatory feedback loop to expand the CSC population [123]. Similarly, autocrine TGF- $\beta$ signaling and IL- 8 expression are also enhanced after chemotherapeutic drug paclitaxel treatment in triple-negative breast cancer, leading to CSC population enrichment and tumor recurrence [124]. Furthermore, stroma-secreted chemokine stroma-derived factor 1a (SDF-1a) and its cognate receptor CXCR4 play an important role in the migration of hematopoietic cells to the bone marrow microenvironment $[125,126]$, so SDF-1A/ CXCR4 interaction mediates the resistance of leukemia cells to chemotherapy-induced apoptosis [127], and thus CXCR4 inhibition with inhibitors such as AMD3100 can enhance the sensitivity of leukemic cells to chemotherapy by disrupting stromal/leukemia cell interactions within the bone marrow microenvironment by Akt phosphorylation inhibition and PARP cleavage induction due to bortezomib in the presence of bone marrow stromal cells (BMSCs) in coculture [128]. Moreover, the CSCs from the chemoresistant tumors have the unique ability to produce a variety of proinflammatory signals, such as IFN regulatory factor-5 (IRF5), which acts as a transcription factor specific for chemoresistant tumors to induce the M-CSF production, to consequently produce the M2-like immunoregulatory myeloid cells from $\mathrm{CD} 14^{+}$monocytes, and to promote the myeloid cell-mediated tumorigenic and stem cell activities of bulk tumors [129].

3.5.4. Immune Cells. It has been indicated previously that tumor-associated macrophages (TAMs) can promote chemoresistance in both myeloma cell lines and primary myeloma cells from spontaneous or chemotherapeutic drug-induced apoptosis by directly interacting with malignant cells within the tumor microenvironment and attenuating the activation and cleavage of caspasedependent apoptotic signaling [130]. Moreover, TAM also directly induces CSC properties of pancreatic tumor cells by activating signal transducer and activator of transcription 3 (STAT3) and thus inhibits the antitumor $\mathrm{CD}^{+} \mathrm{T}$ lymphocyte responses in the chemotherapeutic response [131]. Besides, in pancreatic ductal adenocarcinoma, cancer cells secrete colony-stimulating factor 1 (CSF1) to attract and stimulate CSF1 receptor- (CSF1R-) expressing TAM to express high levels of cytidine deaminase (CDA), an intracellular enzyme which catabolizes the bioactive form of gemcitabine and therefore protects the cancer cells from the chemotherapy [132].

3.6. Epigenetics. Besides, CSC-mediated drug resistance is regulated by epigenetic mechanisms as well, including histone modifications and DNA methylation. First, DNA methylation was unchanged during TGF- $\beta$-mediated EMT but other epigenetic changes such as a lysinespecific deaminase-1- (Lsd1-) dependent global reduction of the heterochromatin mark H3-lys9 dimethylation (H3K9Me2), an increase of the euchromatin mark H3lys4 trimethylation ( $\mathrm{H} 3 \mathrm{~K} 4 \mathrm{Me} 3)$ and the transcriptional mark H3-lys36 trimethylation (H3K36Me3) are found; especially, $\mathrm{H} 3 \mathrm{~K} 4 \mathrm{Me} 3$ might contribute to Lsd1-regulated chemoresistance [133]. In addition, KDM1A, a flavin adenine dinucleotide- (FAD-) dependent lysine-specific demethylase specifically with monomethyl- and dimethylhistone H3 lysine-4 (H3K4) and lysine-9 (H3K9) substrate, is an important regulator of MLL-AF9 leukemia stem cell (LSC) oncogenic potential by blocking differentiation [134]. Besides, B-cell-specific Moloney murine leukemia virus integration site 1 (BMI1), one of several epigenetic silencer proteins belonging to Polycomb group (PcG), is required for self-renewal of both adult stem cells and many CSCs via various key pathways, such as anchorage-independent growth, Wnt and Notch pathway [135]. BMI-1 has been indicated to be involved in the protection of cancer cells from apoptosis or drug resistance in various types of cancer, including nasopharyngeal carcinoma [136], melanoma [137], pancreatic adenocarcinoma [138], ovarian cancer [139], and hepatocellular carcinoma [140]. Furthermore, another PcG member EZH2, a catalytic subunit of polycomb repressor complex 2 (PRC2) which trimethylates histone $\mathrm{H3}$ at lysine 27 (H3K27me) and elicits gene silencing, also participates in pancreatic cancer chemoresistance by silencing p27 tumor suppressor gene via methylation of histone $\mathrm{H} 3$-lysine 27 (H3K27) [141]. Moreover, EZH2 protects GSCs from radiation-induced cell death and consequently promotes GSC survival and radioresistance via upstream regulator mitotic kinase maternal embryonic leucine-zipper kinase (MELK) [142]. In addition, EZH2 inhibition sensitizes BRG1 and EGFR loss-of-function mutant lung tumors to topoisomerase II (TopoII) inhibitor etoposide with increased $S$ phase, anaphase bridging, and apoptosis [143]. Interestingly, EZH2 and BMI1 are indicated to inversely correlate with prognosis signature and TP53 mutation in breast cancer [144].

Second, histone acetylation is involved in the regulation of transcriptional activation and chemoresistance of CSCs too. Treatment with HDAC inhibitors (HDACi) effectively targets the quiescent chronic myelogenous leukemia (CML) stem cells which are resistant to tyrosine kinase inhibitor imatinib mesylate (IM) [145]. Similarly, pretreatment with HDAC inhibitors may sensitize the prostate stem-like cells to radiation treatment through increased DNA damage and reduced clonogenic survival [146]. Vorinostat, a HDAC inhibitor via inducing ubiquitination and lysosome degradation, downregulates the expression and signaling of all three receptors EGFR, ErbB2, and ErbB3 together with reversion of EMT in EGFR TKI gefitinib-resistant cells and therefore enhances the antitumor effect of gefitinib in squamous cell carcinoma of head and neck [147]. Interestingly, NANOG upregulates histone deacetylases 1 (HDAC1) via binding to the promoter region and decreasing K14 and K27 histone $\mathrm{H} 3$ acetylation; as a result, it induces not only the stem-like features through epigenetic repression of cell 
cycle inhibitor CDKN2D and CDKN1B but also the immune resistance and chemoresistance through MCL-1 upregulation by epigenetic silencing of E3 ubiquitin-ligase TRIM17 and NOXA [148].

Third, many tumor suppressor genes have been shown to be epigenetically silenced in chemoresistant cancers by DNA methylation on $\mathrm{CpG}$ promoter regions. For instance, tumor suppressor insulin-like growth factor binding protein-3 (IGFBP-3), which is involved in controlling cell growth, transformation, and survival, is specifically downregulated through promoter-hypermethylation and results in acquired resistance to chemotherapy in many different types of cancer [149]. In addition, loss of DNA mismatch repair (MMR) gene hMLH1 via full hypermethylation of the hMLH1 promoter [150] is highly correlated with the ability of arresting cell death and cell cycle after DNA damage induced by chemotherapy and poor survival prediction for cancer patients [151], hence plays a role in drug resistance in ovarian [152] and breast cancers [153].

\subsection{Signaling Pathways of CSC-Driven Chemoresistance. As} mentioned, normal stem cells and CSCs have similar characteristics such as self-renewal and differentiation. They also share numbers of key signaling pathway to maintain its existence. For example, Notch signaling was highly expressed in the hematopoietic tumors such as T-ALL and solid tumors such as non-small-cell lung carcinoma (NSCLC), breast cancer, and glioblastoma [154-156]. Activation of Hedgehog signaling which in normal condition plays important roles in embryonic development and tissue regeneration also has been found to be involved in the regulation of various cancer stem cells, such as pancreatic cancer, leukemias, and basal cell carcinoma (BCC) [157]. Another signaling pathway such as WNT, TGF $\beta$, PI3K/Akt, EGFR, and JAK/STAT, as well as transcriptional regulators including OCT4, Nanog, YAP/ $\mathrm{TAZ}$, and Myc are also commonly activated in various cancer stem cells to regulate their self-renewal and differentiation state $[21,158]$. CSCs have been indicated to display many characteristics of embryonic or tissue stem cells and developmental signaling pathways such as Wnt, $\mathrm{HH}$, and Notch that are highly conserved embryonically and control self-renewal of stem cells [159]. Therefore, activation of these pathways may play an important role in the expansion of CSCs and hence the resistance to therapy [160]. Here, several representatives are explained.

First, it has been indicated that activation of $\mathrm{Wnt} / \beta$ catenin signaling enhances the chemoresistance to IFN- $\alpha / 5$ FU combination therapy [161]. OV6 ${ }^{+}$HCC cells, a subpopulation of less differentiated progenitor-like cells in HCC cell lines and primary HCC tissues, have been shown to be endogenously active $\mathrm{Wnt} / \beta$-catenin signaling and resistant to standard chemotherapy [162]. In addition, in neuroblastoma, amplification and upregulation of frizzled-1 Wnt receptor (FZD1) activate the $\mathrm{Wnt} / \beta$-catenin pathway in chemoresistant cancer cells by nuclear $\beta$-catenin translocation and transactivation of Wnt target genes such as multidrug resistance gene (MDR1), which is known to mediate the resistance to chemotherapy [163]. Furthermore, c-Kit, a stem cell factor (SCF) receptor, mediates chemoresistance through activation of Wnt $/ \beta$-catenin and ATP-binding cassette G2 (ABCG2) pathway in ovarian cancer [164].

Secondly, Hh pathway could regulate autophagy in CML cells and then inhibition of the Hh pathway and autophagy simultaneously could sharply reduce cell viability and significantly induce apoptosis of imatinib-sensitive or -resistant BCR-ABL ${ }^{+}$cells via downregulating the kinase activity of the BCR-ABL oncoprotein [165]. Concomitantly, the expression of sonic hedgehog $(\mathrm{SHH})$ and glioma-associated oncogene homolog 1 (GLI1), the well-known signaling pathway molecules involved in the drug resistance, is higher in enriched $\mathrm{CD} 44^{+} /$Musashi- $1^{+}$gastric cancer stem cells and consequently enhances the drug resistance via high drug efflux pump activity [166]. In glioma, $\mathrm{CD} 133^{+} \mathrm{CSC}$ population, which contributes to the chemoresistance of therapy such as temozolomide (TMZ) treatment, overexpresses genes involved in Notch and SHH pathways and activates these pathways [167].

Last but not least, chemotherapy such as oxaliplatin induces Notch-1 receptor and its downstream target Hes-1 activity by increasing gamma-secretase activity in colon cancer cells; hence, inhibition of Notch-1 signaling by gammasecretase inhibitors (GSIs) sensitizes colon cancer cells to chemotherapy [168]. Moreover, Notch signaling pathway and Notch3 in particular play an essential role in the regulation of CSC maintenance and chemoresistance to platinum in ovarian cancer therapy [169]. Similarly, the enrichment of $\mathrm{CD}_{133^{+}}$cells in lung adenocarcinoma after cisplatin induction leads to multidrug resistance through activation of Notch signaling as higher levels of cleaved Notch1 (NICD1) are detected [170]. Furthermore, it has been shown that gefitinib-acquired resistant lung adenocarcinoma cells undergo EMT by activation of Notch-1 signaling via Notch-1 receptor intracellular domain (N1IC), the activated form of the Notch-1 receptor [63].

Besides, there are also some molecules which act as the integration of various pathways involved in the control of stem cell fate across tissues; for example, CYP26, a primary retinoid-inactivating enzyme through retinoid and Hedgehog pathways, limits the retinoic acid concentration, therefore leading to drug resistance in the stem cell niche [171].

\section{CSC-Based Therapy}

Owing to the ability of CSCs to develop chemo- and radioresistance which play key roles in the malignant progression, metastasis, and cancer recurrence, it is suggested that targeting cancer stem cells offers an ultimate goal to overcome a poor prognosis, leading to a better patient survival $[15,22]$. Selective targeting of CSC signaling networks that are essential for self-renewal, proliferation, and differentiation to maintain their stem cell properties provides a new challenge in the development of cancer treatments $[19,172]$. Over the last decades, it was suggested that the combination of conventional therapy and targeted therapy against CSC-specific pathways gives rise a better consequence compared to monotherapy in removal of both bulk tumor and CSC population (Figure 1) [19]. Thus, targeting essential pathways in the CSCs such as Notch, Wnt, and Hedgehog $(\mathrm{HH})$ is being 
developed to block the self-renewal of CSCs [21]. Lately, some classes of Notch pathway inhibitors have been reported to enter a clinical trial, accompanied by a substantial variety of targets, mechanism of action, and drug classes [19, 21]. The major class of Notch inhibitor is the $\gamma$-secretase inhibitors (GSIs). GSI works by inhibiting the final proteolytic cleavage of Notch receptors, which results in the release of the active intracellular fragment. It was the first class of Notch pathway inhibitor that enters a clinical trial in the cancer field [159, 173, 174].

$\mathrm{HH}$ pathway is shown to be involved in several essential developmental pathways such as tissue patterning during embryonic development and the repair of normal tissues and epithelial-to-mesenchymal transition [175]. Vismodegib, a drug targeting $\mathrm{HH}$ pathway, was approved by the European Medicines Agency (EMA) in 2013 and the US FDA in 2012 for the therapy of metastatic BCC patients or locally advanced BCC patients that are not candidates for surgery or radiotherapy $[176,177]$.

Targeting Wnt signaling has also shown promising results related to carcinogenesis, tumor invasiveness, and metastasis [159]. Wnt3A-neutralizing mAb was shown to have antiproliferation and proapoptotic effects in prostate cancer mouse model [178]. And anti-Fz10 radio-labeled $\mathrm{mAb}$ is being evaluated in a phase I trial for the synovial sarcoma therapy. Vantictumab (OMP-18R5, a mAb that blocks five $\mathrm{Fz}$ receptors such as $\mathrm{Fz} 1, \mathrm{Fz} 2, \mathrm{Fz} 5, \mathrm{Fz} 7$, and Fz8) [179-181] and OMP-54F28 [181] (a mAb that blocks fusion protein decoy receptor such as truncated Fz8) are under investigation in phase I studies in advanced-stage solid tumors [182].

Targeting CSCs through the EMT pathways also provides a new challenge in the cancer therapy study. This therapy is developed in order to prevent cancer aggressiveness and acquired drug resistance of cancer stem cells [183, 184]. Lately, the finding of therapeutic agents to EMT-based CSC therapy indicated three general target groups [184, 185]. These include a group involved in the regulation of EMT extracellular inducer such as TGF- $\beta$, EGF, Axl-Gas6 pathways, hypoxia, and extracellular matrix components. Another group is the transcription factors (TFs) that promote EMT transcriptome including Twist1, Snail1, Zeb1/2, T-box TF Brachyury as well as its downstream effectors of EMT, such as E-Cadherin, N-Cadherin, vimentin, and HoxA9. The last one is targeting regulators of EMT-TFs and epigenetic regulator using microRNA [184-190].

Accumulating evidence suggests that miRNA and other groups of long noncoding RNA (lncRNA) play important roles in the regulation of CSCs properties such as self-renewal, asymmetric cell division, tumor initiation, drug resistance, and disease recurrence [186, 187, 189, 191-193].The usage of miRNA as CSC-based therapeutic agents is reported; for example, mir-22 that targets TET2 in leukemia (AML and MDS) and breast cancer [194], Let-7 to target RAS and HMGA2 in breast cancer [195], mir-128 to target BMI-1 in brain cancer [191], mir-200 to target ZEB1/ZEB2, BMI-1, and SUZ12 in breast cancer [189, 196, 197], and some other miRNA in the colon cancer and prostate cancer have been reported to reduce cancer malignancy [198-202].
Finally, cancer immunotherapy may be a breakthrough for targeting specifically CSCs in cancer patients. For cancer immunotherapy, several effectors, including natural killer (NK) cells and $\gamma \delta \mathrm{T}$ cells in innate immunity, antibodies in acquired humoral immunity, CSC-based dendritic cells, and CSC-primed cytotoxic T lymphocytes (CTLs) in acquired cellular immunity, which are able to recognize and kill CSCs may be suitable candidates to improve the efficacy of cancer treatment. A variety of immunotherapeutic strategies that specifically target CSCs using these effector cells have been reported. In addition, identification of specific antigens or genetic alterations in CSCs plays an important role in finding targets for immunotherapy. These include CSC markers (ALDH [203], CD44 [204, 205], CD133 [206], EpCAM [207], and HER2 [208]), CSC niche interaction (TAM [209]), tumor microenvironment (immune cells/myeloidderived suppressor cells), cytokines (IL1 [210], IL6 [211], and IL8 [212]), and immune checkpoint (CTLA-4 [213] or PD1/PDL1 [214]).

\section{Conclusion}

CSCs possess stem cell-like features found in cancer and have important implications for the chemoresistance and cancer relapse, a notion that remains somewhat controversial. With a small subpopulation in the malignant cell pool, the contribution of CSCs is remarkable in cancer therapy, as shown by intensive studies in recent decades. These cells can be identified based on the presence of surface biomarkers, enhanced spheroid or colony formation in vitro and augmented tumor-initiating potential as well as tumorigenic ability in vivo. They are resistance to chemotherapy and radiation therapy compared to bulk tumor cells and hence play a crucial role in tumor recurrence after anticancer therapy. To survive following cancer treatment, CSCs seem to be able to manifest several responses such as EMT, induction of signaling pathways that regulate self-renewal or influence tumor environments, expression of drug transporters or detoxification proteins, and so forth to protect them from devastating effects caused by therapeutic agents. Thus, the development of anticancer therapeutics that target CSCs is not only limited to the finding of inhibitor of CSC pathways and cell surface markers but also to the development of EMT and CSCs microenvironment-related inhibitors. Though the molecular mechanisms underlying the resistance of CSCs to chemotherapy and radiation still require further studies in order to develop promising strategies for suppressing tumor relapse and metastasis, recent technological advances made it easier than before to find mechanisms contributing to drug resistance. Also, the recent therapeutic strategy of combining molecules specifically targeting CSCs with conventional chemotherapeutic drugs could possibly be a better direction for anticancer therapy and may therefore achieve better survival rates of cancer patients (Figure 1) [19]. Besides, as some cell surface biomarkers and signaling pathways are similar between CSCs and normal stem cells, it is also essentially required to develop novel therapeutic agents targeting only CSCs to avoid off-target effects on noncancerous cells or normal stem cells. 


\section{Conflicts of Interest}

The authors declare no conflict of interest.

\section{Authors' Contributions}

Lan Thi Hanh Phi and Ita Novita Sari contributed equally to the work.

\section{Acknowledgments}

This work was supported by the Soonchunhyang University Research Fund and Global Research Development Center (NRF-2016K1A4A3914725).

\section{References}

[1] R. Siegel, D. Naishadham, and A. Jemal, "Cancer statistics, 2013," CA: a Cancer Journal for Clinicians, vol. 63, no. 1, pp. 11-30, 2013.

[2] D. Hanahan and R. A. Weinberg, "Hallmarks of cancer: the next generation," Cell, vol. 144, no. 5, pp. 646-674, 2011.

[3] Y. N. You, V. T. Lakhani, and S. A. Wells Jr., "The role of prophylactic surgery in cancer prevention," World Journal of Surgery, vol. 31, no. 3, pp. 450-464, 2007.

[4] B. M. Putzer, M. Solanki, and O. Herchenroder, "Advances in cancer stem cell targeting: how to strike the evil at its root," Advanced Drug Delivery Reviews, vol. 120, pp. 89-107, 2017.

[5] Y. A. Luqmani, "Mechanisms of drug resistance in cancer chemotherapy," Medical Principles and Practice, vol. 14, no. 1, pp. 35-48, 2005.

[6] P. A. Reid, P. Wilson, Y. Li, L. G. Marcu, and E. Bezak, "Current understanding of cancer stem cells: review of their radiobiology and role in head and neck cancers," Head \& Neck, vol. 39, no. 9, pp. 1920-1932, 2017.

[7] O. Tredan, C. M. Galmarini, K. Patel, and I. F. Tannock, "Drug resistance and the solid tumor microenvironment," Journal of the National Cancer Institute, vol. 99, no. 19, pp. 1441-1454, 2007.

[8] D. A. Senthebane, A. Rowe, N. E. Thomford et al., "The role of tumor microenvironment in chemoresistance: to survive, keep your enemies closer," International Journal of Molecular Sciences, vol. 18, no. 7, 2017.

[9] A. Fesler, S. Guo, H. Liu, N. Wu, and J. Ju, "Overcoming chemoresistance in cancer stem cells with the help of microRNAs in colorectal cancer," Epigenomics, vol. 9, no. 6, pp. 793-796, 2017.

[10] R. Di Fiore, R. Drago-Ferrante, F. Pentimalli et al., "MicroRNA-29b-1 impairs in vitro cell proliferation, self-renewal and chemoresistance of human osteosarcoma $3 \mathrm{AB}-\mathrm{OS}$ cancer stem cells," International Journal of Oncology, vol. 45, no. 5, pp. 2013-2023, 2014.

[11] D. Chen, M. Wu, Y. Li et al., "Targeting BMI1 ${ }^{+}$cancer stem cells overcomes chemoresistance and inhibits metastases in squamous cell carcinoma," Cell Stem Cell, vol. 20, no. 5, pp. 621-634.e6, 2017.

[12] J. E. Visvader and G. J. Lindeman, "Cancer stem cells in solid tumours: accumulating evidence and unresolved questions," Nature Reviews Cancer, vol. 8, no. 10, pp. 755-768, 2008.
[13] M. R. Alison, S. M. Lim, and L. J. Nicholson, "Cancer stem cells: problems for therapy?," The Journal of Pathology, vol. 223, no. 2, pp. 147-161, 2011.

[14] M. Dean, T. Fojo, and S. Bates, "Tumour stem cells and drug resistance," Nature Reviews Cancer, vol. 5, no. 4, pp. 275-284, 2005.

[15] A. Singh and J. Settleman, "EMT, cancer stem cells and drug resistance: an emerging axis of evil in the war on cancer," Oncogene, vol. 29, no. 34, pp. 4741-4751, 2010.

[16] M. H. Kiyohara, C. Dillard, J. Tsui et al., "EMP2 is a novel therapeutic target for endometrial cancer stem cells," Oncogene, vol. 36, no. 42, pp. 5793-5807, 2017.

[17] J. Chen, Y. Li, T. S. Yu et al., "A restricted cell population propagates glioblastoma growth after chemotherapy," Nature, vol. 488, no. 7412, pp. 522-526, 2012.

[18] D. Fang and H. Kitamura, "Cancer stem cells and epithelial-mesenchymal transition in urothelial carcinoma: possible pathways and potential therapeutic approaches," International Journal of Urology, vol. 25, no. 1, pp. 717, 2018.

[19] M. Cojoc, K. Mäbert, M. H. Muders, and A. Dubrovska, “A role for cancer stem cells in therapy resistance: cellular and molecular mechanisms," Seminars in Cancer Biology, vol. 31, pp. 16-27, 2015.

[20] L. I. Shlush, A. Mitchell, L. Heisler et al., "Tracing the origins of relapse in acute myeloid leukaemia to stem cells," Nature, vol. 547, no. 7661, pp. 104-108, 2017.

[21] D. R. Pattabiraman and R. A. Weinberg, "Tackling the cancer stem cells - what challenges do they pose?," Nature Reviews Drug Discovery, vol. 13, no. 7, pp. 497-512, 2014.

[22] Z. J. Yang and R. J. Wechsler-Reya, "Hit 'em where they live: targeting the cancer stem cell niche," Cancer Cell, vol. 11, no. 1, pp. 3-5, 2007.

[23] P. Valent, D. Bonnet, R. de Maria et al., "Cancer stem cell definitions and terminology: the devil is in the details," Nature Reviews Cancer, vol. 12, no. 11, pp. 767-775, 2012.

[24] C. Peitzsch, I. Kurth, L. Kunz-Schughart, M. Baumann, and A. Dubrovska, "Discovery of the cancer stem cell related determinants of radioresistance," Radiotherapy and Oncology, vol. 108, no. 3, pp. 378-387, 2013.

[25] D. Bonnet and J. E. Dick, "Human acute myeloid leukemia is organized as a hierarchy that originates from a primitive hematopoietic cell," Nature Medicine, vol. 3, no. 7, pp. 7307, 1997.

[26] S. A. Joosse and K. Pantel, "Biologic challenges in the detection of circulating tumor cells," Cancer Research, vol. 73, no. 1, pp. 8-11, 2013.

[27] M. Al-Hajj, M. S. Wicha, A. Benito-Hernandez, S. J. Morrison, and M. F. Clarke, "Prospective identification of tumorigenic breast cancer cells," Proceedings of the National Academy of Sciences of the United States of America, vol. 100, no. 7, pp. 3983-3988, 2003.

[28] T. N. Ignatova, V. G. Kukekov, E. D. Laywell, O. N. Suslov, F. D. Vrionis, and D. A. Steindler, "Human cortical glial tumors contain neural stem-like cells expressing astroglial and neuronal markers in vitro," Glia, vol. 39, no. 3, pp. 193-206, 2002.

[29] T. Schatton, G. F. Murphy, N. Y. Frank et al., "Identification of cells initiating human melanomas," Nature, vol. 451, no. 7176 , pp. $345-349,2008$. 
[30] S. K. Singh, I. D. Clarke, M. Terasaki et al., "Identification of a cancer stem cell in human brain tumors," Cancer Research, vol. 63, no. 18, pp. 5821-5828, 2003.

[31] A. Eramo, F. Lotti, G. Sette et al., "Identification and expansion of the tumorigenic lung cancer stem cell population," Cell Death \& Differentiation, vol. 15, no. 3, pp. 504-514, 2008.

[32] Z. F. Yang, D. W. Ho, M. N. Ng et al., "Significance of CD90 cancer stem cells in human liver cancer," Cancer Cell, vol. 13, no. 2, pp. 153-166, 2008.

[33] C. Li, D. G. Heidt, P. Dalerba et al., "Identification of pancreatic cancer stem cells," Cancer Research, vol. 67, no. 3, pp. 1030-1037, 2007.

[34] C. A. O'Brien, A. Pollett, S. Gallinger, and J. E. Dick, "A human colon cancer cell capable of initiating tumour growth in immunodeficient mice," Nature, vol. 445, no. 7123, pp. 106-110, 2007.

[35] S. Zhang, C. Balch, M. W. Chan et al., "Identification and characterization of ovarian cancer-initiating cells from primary human tumors," Cancer Research, vol. 68, no. 11, pp. 4311-4320, 2008.

[36] T. B. Brunner, L. A. Kunz-Schughart, P. Grosse-Gehling, and M. Baumann, "Cancer stem cells as a predictive factor in radiotherapy," Seminars in Radiation Oncology, vol. 22, no. 2, pp. 151-174, 2012.

[37] P. Dalerba, R. W. Cho, and M. F. Clarke, "Cancer stem cells: models and concepts," Annual Review of Medicine, vol. 58, no. 1, pp. 267-284, 2007.

[38] M. López-Lázaro, "The migration ability of stem cells can explain the existence of cancer of unknown primary site. Rethinking metastasis," Oncoscience, vol. 2, no. 5, pp. 467475, 2015.

[39] M. Lopez-Lazaro, "Stem cell division theory of cancer," Cell Cycle, vol. 14, no. 16, pp. 2547-2548, 2015.

[40] Y. Wang, J. Yang, H. Zheng et al., "Expression of mutant p53 proteins implicates a lineage relationship between neural stem cells and malignant astrocytic glioma in a murine model," Cancer Cell, vol. 15, no. 6, pp. 514-526, 2009.

[41] M. Nouri, J. Caradec, A. A. Lubik et al., "Therapy-induced developmental reprogramming of prostate cancer cells and acquired therapy resistance," Oncotarget, vol. 8, no. 12, pp. 18949-18967, 2017.

[42] N. Barker, R. A. Ridgway, J. H. van Es et al., "Crypt stem cells as the cells-of-origin of intestinal cancer," Nature, vol. 457, no. 7229, pp. 608-611, 2009.

[43] D. Rubio, J. Garcia-Castro, M. C. Martín et al., "Spontaneous human adult stem cell transformation," Cancer Research, vol. 65, no. 8, pp. 3035-3039, 2005.

[44] J. S. Burns, B. M. Abdallah, P. Guldberg, J. Rygaard, H. D. Schrøder, and M. Kassem, "Tumorigenic heterogeneity in cancer stem cells evolved from long-term cultures of telomerase-immortalized human mesenchymal stem cells," Cancer Research, vol. 65, no. 8, pp. 3126-3135, 2005.

[45] C. Liu, Z. Chen, Z. Chen, T. Zhang, and Y. Lu, "Multiple tumor types may originate from bone marrow-derived cells," Neoplasia, vol. 8, no. 9, pp. 716-724, 2006.

[46] I. Baccelli and A. Trumpp, "The evolving concept of cancer and metastasis stem cells," Journal of Cell Biology, vol. 198, no. 3, pp. 281-293, 2012.

[47] C. H. M. Jamieson, L. E. Ailles, S. J. Dylla et al., "Granulocytemacrophage progenitors as candidate leukemic stem cells in blast-crisis CML," The New England Journal of Medicine, vol. 351, no. 7, pp. 657-667, 2004.

[48] U. Schüller, V. M. Heine, J. Mao et al., “Acquisition of granule neuron precursor identity is a critical determinant of progenitor cell competence to form Shh-induced medulloblastoma," Cancer Cell, vol. 14, no. 2, pp. 123-134, 2008.

[49] Z. J. Yang, T. Ellis, S. L. Markant et al., "Medulloblastoma can be initiated by deletion of Patched in lineage-restricted progenitors or stem cells," Cancer Cell, vol. 14, no. 2, pp. 135-145, 2008.

[50] D. Friedmann-Morvinski, E. A. Bushong, E. Ke et al., "Dedifferentiation of neurons and astrocytes by oncogenes can induce gliomas in mice," Science, vol. 338, no. 6110, pp. 1080-1084, 2012.

[51] K. Chen, Y.-h. Huang, and J.-l. Chen, "Understanding and targeting cancer stem cells: therapeutic implications and challenges," Acta Pharmacologica Sinica, vol. 34, no. 6, pp. 732-740, 2013.

[52] P. Dalerba, S. J. Dylla, I. K. Park et al., "Phenotypic characterization of human colorectal cancer stem cells," Proceedings of the National Academy of Sciences of the United States of America, vol. 104, no. 24, pp. 10158-10163, 2007.

[53] C. Ginestier, M. H. Hur, E. Charafe-Jauffret et al., "ALDH1 is a marker of normal and malignant human mammary stem cells and a predictor of poor clinical outcome," Cell Stem Cell, vol. 1, no. 5, pp. 555-567, 2007.

[54] L. I. Shlush, S. Zandi, A. Mitchell et al., "Identification of preleukaemic haematopoietic stem cells in acute leukaemia," Nature, vol. 506, no. 7488, pp. 328-333, 2014.

[55] B. Auffinger, A. L. Tobias, Y. Han et al., "Conversion of differentiated cancer cells into cancer stem-like cells in a glioblastoma model after primary chemotherapy," Cell Death o Differentiation, vol. 21, no. 7, pp. 1119-1131, 2014.

[56] P. Hamerlik, J. D. Lathia, R. Rasmussen et al., "Autocrine VEGF-VEGFR2-Neuropilin-1 signaling promotes glioma stem-like cell viability and tumor growth," Journal of Experimental Medicine, vol. 209, no. 3, pp. 507-520, 2012.

[57] K. Shien, S. Toyooka, H. Yamamoto et al., "Acquired resistance to EGFR inhibitors is associated with a manifestation of stem cell-like properties in cancer cells," Cancer Research, vol. 73, no. 10, pp. 3051-3061, 2013.

[58] T. Oskarsson, E. Batlle, and J. Massague, "Metastatic stem cells: sources, niches, and vital pathways," Cell Stem Cell, vol. 14, no. 3, pp. 306-321, 2014.

[59] A. Puisieux, T. Brabletz, and J. Caramel, "Oncogenic roles of EMT-inducing transcription factors," Nature Cell Biology, vol. 16, no. 6, pp. 488-494, 2014.

[60] S. A. Mani, W. Guo, M. J. Liao et al., "The epithelialmesenchymal transition generates cells with properties of stem cells," Cell, vol. 133, no. 4, pp. 704-715, 2008.

[61] S. Meidhof, S. Brabletz, W. Lehmann et al., "ZEB1-associated drug resistance in cancer cells is reversed by the class I HDAC inhibitor mocetinostat," EMBO Molecular Medicine, vol. 7, no. 6, pp. 831-847, 2015.

[62] H. Uramoto, T. Iwata, T. Onitsuka, H. Shimokawa, T. Hanagiri, and T. Oyama, "Epithelial-mesenchymal transition in EGFR-TKI acquired resistant lung adenocarcinoma," Anticancer Research, vol. 30, no. 7, pp. 2513-7, 2010.

[63] M. Xie, L. Zhang, C. S. He et al., "Activation of Notch-1 enhances epithelial-mesenchymal transition in gefitinib- 
acquired resistant lung cancer cells," Journal of Cellular Biochemistry, vol. 113, no. 5, pp. 1501-1513, 2012.

[64] P. C. Black, G. A. Brown, T. Inamoto et al., "Sensitivity to epidermal growth factor receptor inhibitor requires E-cadherin expression in urothelial carcinoma cells," Clinical Cancer Research, vol. 14, no. 5, pp. 1478-1486, 2008.

[65] B. C. Fuchs, T. Fujii, J. D. Dorfman et al., "Epithelial-tomesenchymal transition and integrin-linked kinase mediate sensitivity to epidermal growth factor receptor inhibition in human hepatoma cells," Cancer Research, vol. 68, no. 7, pp. 2391-2399, 2008.

[66] J. F. Lo, C. C. Yu, S. H. Chiou et al., "The epithelialmesenchymal transition mediator S100A4 maintains cancer-initiating cells in head and neck cancers," Cancer Research, vol. 71, no. 5, pp. 1912-1923, 2011.

[67] K. Polyak and R. A. Weinberg, "Transitions between epithelial and mesenchymal states: acquisition of malignant and stem cell traits," Nature Reviews Cancer, vol. 9, no. 4, pp. 265-273, 2009.

[68] F. A. Siebzehnrubl, D. J. Silver, B. Tugertimur et al., “The ZEB1 pathway links glioblastoma initiation, invasion and chemoresistance," EMBO Molecular Medicine, vol. 5, no. 8, pp. 1196-1212, 2013.

[69] B. S. Koo, S. H. Lee, J. M. Kim et al., "Oct4 is a critical regulator of stemness in head and neck squamous carcinoma cells," Oncogene, vol. 34, no. 18, pp. 2317-2324, 2015.

[70] C. E. Huang, C. C. Yu, F. W. Hu, M. Y. Chou, and L. L. Tsai, "Enhanced chemosensitivity by targeting Nanog in head and neck squamous cell carcinomas," International Journal of Molecular Sciences, vol. 15, no. 9, pp. 1493514948, 2014.

[71] M. Y. Chou, F. W. Hu, C. H. Yu, and C. C. Yu, "Sox2 expression involvement in the oncogenicity and radiochemoresistance of oral cancer stem cells," Oral Oncology, vol. 51, no. 1, pp. 31-39, 2015.

[72] G. Y. Chiou, T. W. Yang, C. C. Huang et al., "Musashi-1 promotes a cancer stem cell lineage and chemoresistance in colorectal cancer cells," Scientific Reports, vol. 7, no. 1, p. 2172, 2017.

[73] H. Z. Cao, X. F. Liu, W. T. Yang, Q. Chen, and P. S. Zheng, "LGR5 promotes cancer stem cell traits and chemoresistance in cervical cancer," Cell Death \& Disease, vol. 8, no. 9, article e3039, 2017.

[74] G. M. Seigel, L. M. Campbell, M. Narayan, and F. GonzalezFernandez, "Cancer stem cell characteristics in retinoblastoma," Molecular Vision, vol. 11, pp. 729-737, 2005.

[75] C. Hirschmann-Jax, A. E. Foster, G. G. Wulf et al., "A distinct "side population" of cells with high drug efflux capacity in human tumor cells," Proceedings of the National Academy of Sciences of the United States of America, vol. 101, no. 39, pp. 14228-14233, 2004.

[76] N. Haraguchi, T. Utsunomiya, H. Inoue et al., "Characterization of a side population of cancer cells from human gastrointestinal system," Stem Cells, vol. 24, no. 3, pp. 506-513, 2006.

[77] A. Alisi, W. Cho, F. Locatelli, and D. Fruci, "Multidrug resistance and cancer stem cells in neuroblastoma and hepatoblastoma," International Journal of Molecular Sciences, vol. 14, no. 12, pp. 24706-24725, 2013.

[78] A. M. Bleau, D. Hambardzumyan, T. Ozawa et al., "PTEN/ $\mathrm{PI} 3 \mathrm{~K} /$ Akt pathway regulates the side population phenotype and ABCG2 activity in glioma tumor stem-like cells," Cell Stem Cell, vol. 4, no. 3, pp. 226-235, 2009.

[79] D. Raha, T. R. Wilson, J. Peng et al., "The cancer stem cell marker aldehyde dehydrogenase is required to maintain a drug-tolerant tumor cell subpopulation," Cancer Research, vol. 74, no. 13, pp. 3579-3590, 2014.

[80] D. J. Pearce, D. Taussig, C. Simpson et al., "Characterization of cells with a high aldehyde dehydrogenase activity from cord blood and acute myeloid leukemia samples," Stem Cells, vol. 23, no. 6, pp. 752-760, 2005.

[81] Y. Su, Q. Qiu, X. Zhang et al., “Aldehyde dehydrogenase 1 A1-positive cell population is enriched in tumor-initiating cells and associated with progression of bladder cancer," Cancer Epidemiology Biomarkers \& Prevention, vol. 19, no. 2, pp. 327-337, 2010.

[82] M. R. Clay, M. Tabor, J. H. Owen et al., "Single-marker identification of head and neck squamous cell carcinoma cancer stem cells with aldehyde dehydrogenase," Head \& Neck, vol. 32, no. 9, pp. 1195-1201, 2010.

[83] F. Jiang, Q. Qiu, A. Khanna et al., “Aldehyde dehydrogenase 1 is a tumor stem cell-associated marker in lung cancer," Molecular Cancer Research, vol. 7, no. 3, pp. 330-338, 2009.

[84] K. Nakahata, S. Uehara, S. Nishikawa et al., "Aldehyde dehydrogenase $1(\mathrm{ALDH} 1)$ is a potential marker for cancer stem cells in embryonal rhabdomyosarcoma," PLoS One, vol. 10, no. 4, article e0125454, 2015.

[85] C. P. Huang, M. F. Tsai, T. H. Chang et al., "ALDH-positive lung cancer stem cells confer resistance to epidermal growth factor receptor tyrosine kinase inhibitors," Cancer Letters, vol. 328, no. 1, pp. 144-151, 2013.

[86] J. A. Ajani, X. Wang, S. Song et al., "ALDH-1 expression levels predict response or resistance to preoperative chemoradiation in resectable esophageal cancer patients," Molecular Oncology, vol. 8, no. 1, pp. 142-149, 2014.

[87] A. Kreso, C. A. O'Brien, P. van Galen et al., "Variable clonal repopulation dynamics influence chemotherapy response in colorectal cancer," Science, vol. 339, no. 6119, pp. 543-548, 2013.

[88] A. V. Kurtova, J. Xiao, Q. Mo et al., "Blocking $\mathrm{PGE}_{2}$-induced tumour repopulation abrogates bladder cancer chemoresistance," Nature, vol. 517, no. 7533, pp. 209-213, 2015.

[89] T. Ishimoto, O. Nagano, T. Yae et al., "CD44 variant regulates redox status in cancer cells by stabilizing the XCT subunit of system $\mathrm{xc}^{-}$and thereby promotes tumor growth," Cancer Cell, vol. 19, no. 3, pp. 387-400, 2011.

[90] M. Diehn, R. W. Cho, N. A. Lobo et al., "Association of reactive oxygen species levels and radioresistance in cancer stem cells," Nature, vol. 458, no. 7239, pp. 780-783, 2009.

[91] H. Yin and J. Glass, "The phenotypic radiation resistance of $\mathrm{CD} 44^{+} / \mathrm{CD} 24^{- \text {or low }}$ breast cancer cells is mediated through the enhanced activation of ATM signaling," PLoS One, vol. 6, no. 9, article e24080, 2011.

[92] S. Bao, Q. Wu, R. E. McLendon et al., "Glioma stem cells promote radioresistance by preferential activation of the DNA damage response," Nature, vol. 444, no. 7120, pp. 756-760, 2006.

[93] J. Wang, T. P. Wakeman, J. D. Lathia et al., "Notch promotes radioresistance of glioma stem cells," Stem Cells, vol. 28, no. 1, pp. 17-28, 2010. 
[94] K. Kise, Y. Kinugasa-Katayama, and N. Takakura, "Tumor microenvironment for cancer stem cells," Advanced Drug Delivery Reviews, vol. 99, Part B, pp. 197-205, 2016.

[95] E. Y.-T. Lau, N. P.-Y. Ho, and T. K.-W. Lee, "Cancer stem cells and their microenvironment: biology and therapeutic implications," Stem Cells International, vol. 2017, Article ID 3714190, 11 pages, 2017.

[96] A. Turdo, M. Todaro, and G. StassiS. Babashah, "Targeting cancer stem cells and the tumor microenvironment," in Cancer Stem Cells: Emerging Concepts and Future Perspectives in Translational Oncology, pp. 445-476, Springer International Publishing, Cham, 2015.

[97] H. Adisetiyo, M. Liang, C. P. Liao et al., "Dependence of castration-resistant prostate cancer (CRPC) stem cells on CRPC-associated fibroblasts," Journal of Cellular Physiology, vol. 229, no. 9, pp. 1170-1176, 2014.

[98] C. P. Liao, H. Adisetiyo, M. Liang, and P. Roy-Burman, "Cancer-associated fibroblasts enhance the gland-forming capability of prostate cancer stem cells," Cancer Research, vol. 70, no. 18, pp. 7294-7303, 2010.

[99] W.-J. Chen, C.-C. Ho, Y.-L. Chang et al., "Cancer-associated fibroblasts regulate the plasticity of lung cancer stemness via paracrine signalling," Nature Communications, vol. 5, p. 3472, 2014.

[100] Y. Kinugasa, T. Matsui, and N. Takakura, "CD44 expressed on cancer-associated fibroblasts is a functional molecule supporting the stemness and drug resistance of malignant cancer cells in the tumor microenvironment," Stem Cells, vol. 32, no. 1, pp. 145-156, 2014.

[101] F. Cammarota and M. O. Laukkanen, "Mesenchymal stem/ stromal cells in stromal evolution and cancer progression," Stem Cells International, vol. 2016, Article ID 4824573, 11 pages, 2016.

[102] K. E. Hovinga, F. Shimizu, R. Wang et al., "Inhibition of notch signaling in glioblastoma targets cancer stem cells via an endothelial cell intermediate," Stem Cells, vol. 28, no. 6, pp. 1019-1029, 2010.

[103] C. Calabrese, H. Poppleton, M. Kocak et al., "A perivascular niche for brain tumor stem cells," Cancer Cell, vol. 11, no. 1, pp. 69-82, 2007.

[104] S. Krishnamurthy, Z. Dong, D. Vodopyanov et al., "Endothelial cell-initiated signaling promotes the survival and selfrenewal of cancer stem cells," Cancer Research, vol. 70, no. 23, pp. 9969-9978, 2010.

[105] S. Krishnamurthy, K. A. Warner, Z. Dong et al., "Endothelial interleukin-6 defines the tumorigenic potential of primary human cancer stem cells," Stem Cells, vol. 32, no. 11, pp. 2845-2857, 2014.

[106] Z. Zhang, Z. Dong, I. S. Lauxen, M. S. Filho, and J. E. Nor, "Endothelial cell-secreted EGF induces epithelial to mesenchymal transition and endows head and neck cancer cells with stem-like phenotype," Cancer Research, vol. 74, no. 10, pp. 2869-2881, 2014.

[107] T. S. Zhu, M. A. Costello, C. E. Talsma et al., "Endothelial cells create a stem cell niche in glioblastoma by providing $\mathrm{NOTCH}$ ligands that nurture self-renewal of cancer stemlike cells," Cancer Research, vol. 71, no. 18, pp. 6061-6072, 2011.

[108] J. Lu, X. Ye, F. Fan et al., "Endothelial cells promote the colorectal cancer stem cell phenotype through a soluble form of Jagged-1," Cancer Cell, vol. 23, no. 2, pp. 171-185, 2013.
[109] S. Schwitalla, A. A. Fingerle, P. Cammareri et al., "Intestinal tumorigenesis initiated by dedifferentiation and acquisition of stem-cell-like properties," Cell, vol. 152, no. 1-2, pp. 2538,2013

[110] L. Vermeulen, F. de Sousa E Melo, M. van der Heijden et al., "Wnt activity defines colon cancer stem cells and is regulated by the microenvironment," Nature Cell Biology, vol. 12, no. 5, pp. 468-476, 2010.

[111] X. C. He, J. Zhang, W. G. Tong et al., "BMP signaling inhibits intestinal stem cell self-renewal through suppression of Wnt- $\beta$-catenin signaling," Nature Genetics, vol. 36 , no. 10, pp. 1117-1121, 2004.

[112] L. A. Milner and A. Bigas, "Notch as a mediator of cell fate determination in hematopoiesis: evidence and speculation," Blood, vol. 93, no. 8, pp. 2431-2448, 1999.

[113] O.-J. Kwon, J. M. Valdez, L. Zhang et al., "Increased Notch signalling inhibits anoikis and stimulates proliferation of prostate luminal epithelial cells," Nature Communications, vol. 5, p. 4416, 2014.

[114] B. R. B. Pires, Í. S. S. De Amorim, L. D. E. Souza, J. A. Rodrigues, and A. L. Mencalha, "Targeting cellular signaling pathways in breast cancer stem cells and its implication for cancer treatment," Anticancer Research, vol. 36, no. 11, pp. 56815692, 2016.

[115] B. Bao, A. S. Azmi, S. Ali et al., "The biological kinship of hypoxia with CSC and EMT and their relationship with deregulated expression of miRNAs and tumor aggressiveness," Biochimica et Biophysica Acta (BBA) - Reviews on Cancer, vol. 1826, no. 2, pp. 272-296, 2012.

[116] B. Bao, S. Ali, A. Ahmad et al., "Hypoxia-induced aggressiveness of pancreatic cancer cells is due to increased expression of VEGF, IL-6 and miR-21, which can be attenuated by CDF treatment," PLoS One, vol. 7, no. 12, article e50165, 2012.

[117] K. P. Ng, A. Manjeri, K. L. Lee et al., "Physiologic hypoxia promotes maintenance of CML stem cells despite effective BCR-ABL1 inhibition," Blood, vol. 123, no. 21, pp. 33163326, 2014.

[118] A. Murakami, F. Takahashi, F. Nurwidya et al., "Hypoxia increases gefitinib-resistant lung cancer stem cells through the activation of insulin-like growth factor 1 receptor," PLoS One, vol. 9, no. 1, article e86459, 2014.

[119] V. Rausch, L. Liu, A. Apel et al., "Autophagy mediates survival of pancreatic tumour-initiating cells in a hypoxic microenvironment," The Journal of Pathology, vol. 227, no. 3, pp. 325-335, 2012.

[120] F. Lotti, A. M. Jarrar, R. K. Pai et al., "Chemotherapy activates cancer-associated fibroblasts to maintain colorectal cancerinitiating cells by IL-17A," Journal of Experimental Medicine, vol. 210, no. 13, pp. 2851-2872, 2013.

[121] N. Nair, A. S. Calle, M. H. Zahra et al., “A cancer stem cell model as the point of origin of cancer-associated fibroblasts in tumor microenvironment," Scientific Reports, vol. 7, no. 1, p. 6838, 2017.

[122] P. Luraghi, G. Reato, E. Cipriano et al., "MET signaling in colon cancer stem-like cells blunts the therapeutic response to EGFR inhibitors," Cancer Research, vol. 74, no. 6, pp. 1857-1869, 2014.

[123] H. Korkaya, G.i. Kim, A. Davis et al., “Activation of an IL6 inflammatory loop mediates trastuzumab resistance in HER2+ breast cancer by expanding the cancer stem cell population," Molecular Cell, vol. 47, no. 4, pp. 570-584, 2012. 
[124] N. E. Bhola, J. M. Balko, T. C. Dugger et al., "TGF- $\beta$ inhibition enhances chemotherapy action against triple-negative breast cancer," The Journal of Clinical Investigation, vol. 123, no. 3, pp. 1348-1358, 2013.

[125] Y. G. Yang, I. N. Sari, M. F. Zia, S. R. Lee, S. J. Song, and H. Y. Kwon, "Tetraspanins: spanning from solid tumors to hematologic malignancies," Experimental Hematology, vol. 44, no. 5, pp. 322-328, 2016.

[126] H. Y. Kwon, J. Bajaj, T. Ito et al., “Tetraspanin 3 is required for the development and propagation of acute myelogenous leukemia," Cell Stem Cell, vol. 17, no. 2, pp. 152-164, 2015.

[127] Z. Zeng, I. J. Samudio, M. Munsell et al., "Inhibition of CXCR4 with the novel RCP168 peptide overcomes stromamediated chemoresistance in chronic and acute leukemias," Molecular Cancer Therapeutics, vol. 5, no. 12, pp. 31133121, 2006.

[128] A. K. Azab, J. M. Runnels, C. Pitsillides et al., "CXCR4 inhibitor AMD3100 disrupts the interaction of multiple myeloma cells with the bone marrow microenvironment and enhances their sensitivity to therapy," Blood, vol. 113, no. 18, pp. 43414351, 2009.

[129] T. Yamashina, M. Baghdadi, A. Yoneda et al., "Cancer stemlike cells derived from chemoresistant tumors have a unique capacity to prime tumorigenic myeloid cells," Cancer Research, vol. 74, no. 10, pp. 2698-2709, 2014.

[130] Y. Zheng, Z. Cai, S. Wang et al., "Macrophages are an abundant component of myeloma microenvironment and protect myeloma cells from chemotherapy drug-induced apoptosis," Blood, vol. 114, no. 17, pp. 3625-3628, 2009.

[131] J. B. Mitchem, D. J. Brennan, B. L. Knolhoff et al., “Targeting tumor-infiltrating macrophages decreases tumor-initiating cells, relieves immunosuppression, and improves chemotherapeutic responses," Cancer Research, vol. 73, no. 3, pp. 11281141, 2013.

[132] M. Amit and Z. Gil, "Macrophages increase the resistance of pancreatic adenocarcinoma cells to gemcitabine by upregulating cytidine deaminase," Oncoimmunology, vol. 2, no. 12, article e27231, 2013.

[133] O. G. McDonald, H. Wu, W. Timp, A. Doi, and A. P. Feinberg, "Genome-scale epigenetic reprogramming during epithelial-to-mesenchymal transition," Nature Structural \& Molecular Biology, vol. 18, no. 8, pp. 867-874, 2011.

[134] W. J. Harris, X. Huang, J. T. Lynch et al., "The histone demethylase KDM1A sustains the oncogenic potential of MLL-AF9 leukemia stem cells," Cancer Cell, vol. 21, no. 4, pp. 473-487, 2012.

[135] F. Crea, R. Danesi, and W. L. Farrar, "Cancer stem cell epigenetics and chemoresistance," Epigenomics, vol. 1, no. 1, pp. 63-79, 2009.

[136] L. Qin, X. Zhang, L. Zhang et al., "Downregulation of BMI-1 enhances 5-fluorouracil-induced apoptosis in nasopharyngeal carcinoma cells," Biochemical and Biophysical Research Communications, vol. 371, no. 3, pp. 531-535, 2008.

[137] R. Ferretti, A. Bhutkar, M. C. McNamara, and J. A. Lees, "BMI1 induces an invasive signature in melanoma that promotes metastasis and chemoresistance," Genes \& Development, vol. 30, no. 1, pp. 18-33, 2016.

[138] E. Proctor, M. Waghray, C. J. Lee et al., "Bmil enhances tumorigenicity and cancer stem cell function in pancreatic adenocarcinoma," PLoS One, vol. 8, no. 2, article e55820, 2013.
[139] E. Wang, S. Bhattacharyya, A. Szabolcs et al., "Enhancing chemotherapy response with Bmi-1 silencing in ovarian cancer," PLoS One, vol. 6, no. 3, article e17918, 2011.

[140] J. Wu, D. Hu, and R. Zhang, "Depletion of Bmi-1 enhances 5fluorouracil-induced apoptosis and autophagy in hepatocellular carcinoma cells," Oncology Letters, vol. 4, no. 4, pp. 723-726, 2012.

[141] A. V. Ougolkov, V. N. Bilim, and D. D. Billadeau, "Regulation of pancreatic tumor cell proliferation and chemoresistance by the histone methyltransferase enhancer of zeste homologue 2," Clinical Cancer Research, vol. 14, no. 21, pp. 6790-6796, 2008.

[142] S. H. Kim, K. Joshi, R. Ezhilarasan et al., "EZH2 protects glioma stem cells from radiation-induced cell death in a MELK/ FOXM1-dependent manner," Stem Cell Reports, vol. 4, no. 2, pp. 226-238, 2015.

[143] C. M. Fillmore, C. Xu, P. T. Desai et al., "EZH2 inhibition sensitizes BRG1 and EGFR mutant lung tumours to TopoII inhibitors," Nature, vol. 520, no. 7546, pp. 239-242, 2015.

[144] A. M. Pietersen, H. M. Horlings, M. Hauptmann et al., "EZH2 and BMI1 inversely correlate with prognosis and TP53 mutation in breast cancer," Breast Cancer Research, vol. 10, no. 6, article R109, 2008.

[145] B. Zhang, A. C. Strauss, S. Chu et al., "Effective targeting of quiescent chronic myelogenous leukemia stem cells by histone deacetylase inhibitors in combination with imatinib mesylate," Cancer Cell, vol. 17, no. 5, pp. 427-442, 2010.

[146] F. M. Frame, D. Pellacani, A. T. Collins et al., "HDAC inhibitor confers radiosensitivity to prostate stem-like cells," British Journal of Cancer, vol. 109, no. 12, pp. 3023-3033, 2013.

[147] F. Bruzzese, A. Leone, M. Rocco et al., "HDAC inhibitor vorinostat enhances the antitumor effect of gefitinib in squamous cell carcinoma of head and neck by modulating ErbB receptor expression and reverting EMT," Journal of Cellular Physiology, vol. 226, no. 9, pp. 2378-2390, 2011.

[148] K.-H. Song, C. H. Choi, H.-J. Lee et al., "HDAC1 upregulation by NANOG promotes multidrug resistance and a stem-like phenotype in immune edited tumor cells," Cancer Research, vol. 77, no. 18, 2017.

[149] I. Ibanez de Caceres, M. Cortes-Sempere, C. Moratilla et al., "IGFBP-3 hypermethylation-derived deficiency mediates cisplatin resistance in non-small-cell lung cancer," Oncogene, vol. 29, no. 11, pp. 1681-1690, 2010.

[150] G. Strathdee, M. J. MacKean, M. Illand, and R. Brown, “A role for methylation of the hMLH1 promoter in loss of hMLH1 expression and drug resistance in ovarian cancer," Oncogene, vol. 18, no. 14, pp. 2335-2341, 1999.

[151] G. Gifford, J. Paul, P. A. Vasey, S. B. Kaye, and R. Brown, "The acquisition of hMLH1 methylation in plasma DNA after chemotherapy predicts poor survival for ovarian cancer patients," Clinical Cancer Research, vol. 10, no. 13, pp. 44204426, 2004.

[152] R. Brown, G. L. Hirst, W. M. Gallagher et al., "hMLH1 expression and cellular responses of ovarian tumour cells to treatment with cytotoxic anticancer agents," Oncogene, vol. 15, no. 1, pp. 45-52, 1997.

[153] H. J. Mackay, D. Cameron, M. Rahilly et al., "Reduced MLH1 expression in breast tumors after primary chemotherapy predicts disease-free survival," Journal of Clinical Oncology, vol. 18 , no. 1, pp. 87-93, 2000. 
[154] J. P. Sullivan, M. Spinola, M. Dodge et al., "Aldehyde dehydrogenase activity selects for lung adenocarcinoma stem cells dependent on notch signaling," Cancer Research, vol. 70, no. 23, pp. 9937-9948, 2010.

[155] G. Dontu, K. W. Jackson, E. McNicholas, M. J. Kawamura, W. M. Abdallah, and M. S. Wicha, "Role of Notch signaling in cell-fate determination of human mammary stem/progenitor cells," Breast Cancer Research, vol. 6, no. 6, pp. R605R615, 2004.

[156] D. M. Park, J. Jung, J. Masjkur et al., "Hes3 regulates cell number in cultures from glioblastoma multiforme with stem cell characteristics," Scientific Reports, vol. 3, no. 1, p. 1095, 2013.

[157] L. Yang, G. Xie, Q. Fan, and J. Xie, "Activation of the hedgehog-signaling pathway in human cancer and the clinical implications," Oncogene, vol. 29, no. 4, pp. 469-481, 2010.

[158] W. F. Tam, P. S. Hahnel, A. Schuler et al., "STAT5 is crucial to maintain leukemic stem cells in acute myelogenous leukemias induced by MOZ-TIF2," Cancer Research, vol. 73, no. 1, pp. 373-384, 2013.

[159] N. Takebe, L. Miele, P. J. Harris et al., "Targeting Notch, Hedgehog, and Wnt pathways in cancer stem cells: clinical update," Nature Reviews Clinical Oncology, vol. 12, no. 8, pp. 445-464, 2015.

[160] I. Kurth, C. Peitzsch, M. Baumann, and A. Dubrovska, "The role of cancer stem cells in tumor Radioresistance," in Cancer Stem Cells, pp. 473-491, John Wiley \& Sons, Hoboken, New Jersey, USA, 2014.

[161] T. Noda, H. Nagano, I. Takemasa et al., "Activation of Wnt/ $\beta$-catenin signalling pathway induces chemoresistance to interferon- $\alpha / 5$-fluorouracil combination therapy for hepatocellular carcinoma," British Journal of Cancer, vol. 100, no. 10, pp. 1647-1658, 2009.

[162] W. Yang, H. X. Yan, L. Chen et al., "Wnt/ $\beta$-catenin signaling contributes to activation of normal and tumorigenic liver progenitor cells," Cancer Research, vol. 68, no. 11, pp. 42874295, 2008.

[163] M. Flahaut, R. Meier, A. Coulon et al., "The Wnt receptor FZD1 mediates chemoresistance in neuroblastoma through activation of the Wnt/ $\beta$-catenin pathway," Oncogene, vol. 28, no. 23, pp. 2245-2256, 2009.

[164] W. K. Chau, C. K. Ip, A. S. C. Mak, H. C. Lai, and A. S. T. Wong, "c-Kit mediates chemoresistance and tumorinitiating capacity of ovarian cancer cells through activation of Wnt/ $\beta$-catenin-ATP-binding cassette G2 signaling," Oncogene, vol. 32, no. 22, pp. 2767-2781, 2013.

[165] X. Zeng, H. Zhao, Y. Li et al., "Targeting Hedgehog signaling pathway and autophagy overcomes drug resistance of BCRABL-positive chronic myeloid leukemia," Autophagy, vol. 11, no. 2, pp. 355-372, 2015.

[166] M. Xu, A. Gong, H. Yang et al., "Sonic hedgehog-glioma associated oncogene homolog 1 signaling enhances drug resistance in CD $44^{+} /$Musashi- $1^{+}$gastric cancer stem cells," Cancer Letters, vol. 369, no. 1, pp. 124-133, 2015.

[167] I. V. Ulasov, S. Nandi, M. Dey, A. M. Sonabend, and M. S. Lesniak, "Inhibition of Sonic hedgehog and Notch pathways enhances sensitivity of $\mathrm{CD}_{133^{+}}$glioma stem cells to temozolomide therapy," Molecular Medicine, vol. 17, no. 1-2, pp. 103-112, 2011.

[168] R. D. Meng, C. C. Shelton, Y. M. Li et al., " $\gamma$-Secretase inhibitors abrogate oxaliplatin-induced activation of the Notch-1 signaling pathway in colon cancer cells resulting in enhanced chemosensitivity," Cancer Research, vol. 69, no. 2, pp. 573582, 2009.

[169] S. M. McAuliffe, S. L. Morgan, G. A. Wyant et al., "Targeting Notch, a key pathway for ovarian cancer stem cells, sensitizes tumors to platinum therapy," Proceedings of the National Academy of Sciences of the United States of America, vol. 109, no. 43, pp. E2939-E2948, 2012.

[170] Y. P. Liu, C. J. Yang, M. S. Huang et al., "Cisplatin selects for multidrug-resistant $\mathrm{CD} 133^{+}$cells in lung adenocarcinoma by activating Notch signaling," Cancer Research, vol. 73, no. 1, pp. 406-416, 2013.

[171] S. Alonso, R. J. Jones, and G. Ghiaur, "Retinoic acid, CYP26, and drug resistance in the stem cell niche," Experimental Hematology, vol. 54, pp. 17-25, 2017.

[172] M. Krause, A. Dubrovska, A. Linge, and M. Baumann, "Cancer stem cells: radioresistance, prediction of radiotherapy outcome and specific targets for combined treatments," Advanced Drug Delivery Reviews, vol. 109, pp. 63-73, 2017.

[173] R. Olson and C. Albright, "Recent progress in the medicinal chemistry of $\gamma$-secretase inhibitors," Current Topics in Medicinal Chemistry, vol. 8, no. 1, pp. 17-33, 2008.

[174] S. Richter, P. L. Bedard, E. X. Chen et al., "A phase I study of the oral gamma secretase inhibitor R04929097 in combination with gemcitabine in patients with advanced solid tumors (PHL-078/CTEP 8575)," Investigational New Drugs, vol. 32, no. 2, pp. 243-249, 2014.

[175] P. A. Beachy, S. G. Hymowitz, R. A. Lazarus, D. J. Leahy, and C. Siebold, "Interactions between Hedgehog proteins and their binding partners come into view," Genes \& Development, vol. 24, no. 18, pp. 2001-2012, 2010.

[176] L. Dirix, "Discovery and exploitation of novel targets by approved drugs," Journal of Clinical Oncology, vol. 32, no. 8, pp. 720-721, 2014.

[177] A. Sekulic, M. R. Migden, A. E. Oro et al., "Efficacy and safety of vismodegib in advanced basal-cell carcinoma," The New England Journal of Medicine, vol. 366, no. 23, pp. 21712179, 2012.

[178] X. Li, V. Placencio, J. M. Iturregui et al., "Prostate tumor progression is mediated by a paracrine TGF- $\beta / \mathrm{Wnt} 3$ a signaling axis," Oncogene, vol. 27, no. 56, pp. 7118-7130, 2008.

[179] M. Kahn, "Can we safely target the WNT pathway?," Nature Reviews Drug Discovery, vol. 13, no. 7, pp. 513-532, 2014.

[180] D. C. Smith, L. S. Rosen, R. Chugh et al., "First-in-human evaluation of the human monoclonal antibody vantictumab (OMP-18R5; anti-Frizzled) targeting the WNT pathway in a phase I study for patients with advanced solid tumors," Journal of Clinical Oncology, vol. 31, 15 Supplement, p. 2540, 2013.

[181] U.S. National Library of Medicine, "ClinicalTrials.Gov," 2014, http://clinicaltrials.gov/show/NCT01345201.

[182] A. Jimeno, M. S. Gordon, R. Chugh et al., "A first-in-human phase 1 study of anticancer stem cell agent OMP-54F28 (FZD8-Fc), decoy receptor for WNT ligands, in patients with advanced solid tumors," Journal of Clinical Oncology, vol. 32, 15 Supplement, p. 2505, 2014.

[183] D. Friedmann-Morvinski and I. M. Verma, "Dedifferentiation and reprogramming: origins of cancer stem cells," EMBO Reports, vol. 15, no. 3, pp. 244-253, 2014.

[184] B. Du and J. Shim, "Targeting epithelial-mesenchymal transition (EMT) to overcome drug resistance in cancer," Molecules, vol. 21, no. 8, 2016. 
[185] R. Malek, H. Wang, K. Taparra, and P. T. Tran, "Therapeutic targeting of epithelial plasticity programs: focus on the epithelial-mesenchymal transition," Cells, Tissues, Organs, vol. 203, no. 2, pp. 114-127, 2017.

[186] S. Knoll, S. Emmrich, and B. M. Putzer, "The E2F1-miRNA cancer progression network," Advances in Experimental Medicine and Biology, vol. 774, pp. 135-147, 2013.

[187] A. A. Dar, S. Majid, D. de Semir, M. Nosrati, V. Bezrookove, and M. Kashani-Sabet, "miRNA-205 suppresses melanoma cell proliferation and induces senescence via regulation of E2F1 protein," Journal of Biological Chemistry, vol. 286, no. 19, pp. 16606-16614, 2011.

[188] V. Alla, B. S. Kowtharapu, D. Engelmann et al., "E2F1 confers anticancer drug resistance by targeting $\mathrm{ABC}$ transporter family members and $\mathrm{Bcl}-2$ via the $\mathrm{p} 73 / \mathrm{DNp} 73-\mathrm{miR}$ 205 circuitry," Cell Cycle, vol. 11, no. 16, pp. 3067-3078, 2012.

[189] P. A. Gregory, A. G. Bert, E. L. Paterson et al., "The miR-200 family and miR-205 regulate epithelial to mesenchymal transition by targeting ZEB1 and SIP1," Nature Cell Biology, vol. 10, no. 5, pp. 593-601, 2008.

[190] C. Palena and D. H. Hamilton, "Immune targeting of tumor epithelial-mesenchymal transition via brachyury-based vaccines," Advances in Cancer Research, vol. 128, pp. 69-93, 2015.

[191] J. Godlewski, M. O. Nowicki, A. Bronisz et al., “Targeting of the Bmi-1 oncogene/stem cell renewal factor by microRNA128 inhibits glioma proliferation and self-renewal," Cancer Research, vol. 68, no. 22, pp. 9125-9130, 2008.

[192] C. A. O'Brien, A. Kreso, P. Ryan et al., "ID1 and ID3 regulate the self-renewal capacity of human colon cancer-initiating cells through p21," Cancer Cell, vol. 21, no. 6, pp. 777-792, 2012.

[193] J. Deng, M. Yang, R. Jiang, N. An, X. Wang, and B. Liu, "Long non-coding RNA HOTAIR regulates the proliferation, selfrenewal capacity, tumor formation and migration of the cancer stem-like cell (CSC) subpopulation enriched from breast cancer cells," PLoS One, vol. 12, no. 1, article e0170860, 2017.

[194] S. J. Song, L. Poliseno, M. S. Song et al., "MicroRNA-antagonism regulates breast cancer stemness and metastasis via TET-family-dependent chromatin remodeling," Cell, vol. 154, no. 2, pp. 311-324, 2013.

[195] F. Yu, H. Yao, P. Zhu et al., "let-7 regulates self renewal and tumorigenicity of breast cancer cells," Cell, vol. 131, no. 6, pp. 1109-1123, 2007.

[196] Y. Shimono, M. Zabala, R. W. Cho et al., "Downregulation of miRNA-200c links breast cancer stem cells with normal stem cells," Cell, vol. 138, no. 3, pp. 592-603, 2009.

[197] D. Iliopoulos, M. Lindahl-Allen, C. Polytarchou, H. A. Hirsch, P. N. Tsichlis, and K. Struhl, "Loss of miR-200 inhibition of Suz12 leads to polycomb-mediated repression required for the formation and maintenance of cancer stem cells," Molecular Cell, vol. 39, no. 5, pp. 761-772, 2010.

[198] D. Iliopoulos, A. Rotem, and K. Struhl, "Inhibition of miR193a expression by Max and $\operatorname{RXR} \alpha$ activates K-Ras and PLAU to mediate distinct aspects of cellular transformation," Cancer Research, vol. 71, no. 15, pp. 5144-5153, 2011.

[199] N. Bitarte, E. Bandres, V. Boni et al., "MicroRNA-451 is involved in the self-renewal, tumorigenicity, and chemoresistance of colorectal cancer stem cells," Stem Cells, vol. 29, no. 11, pp. 1661-1671, 2011.
[200] P. Bu, K. Y. Chen, J. H. Chen et al., "A microRNA miR-34aregulated bimodal switch targets Notch in colon cancer stem cells," Cell Stem Cell, vol. 12, no. 5, pp. 602-615, 2013.

[201] C. Liu, K. Kelnar, B. Liu et al., "The microRNA miR-34a inhibits prostate cancer stem cells and metastasis by directly repressing CD44," Nature Medicine, vol. 17, no. 2, pp. 211215, 2011.

[202] Y. Y. Wu, Y. L. Chen, Y. C. Jao, I. S. Hsieh, K. C. Chang, and T. M. Hong, "miR-320 regulates tumor angiogenesis driven by vascular endothelial cells in oral cancer by silencing neuropilin 1," Angiogenesis, vol. 17, no. 1, pp. 247-260, 2014.

[203] C. Visus, Y. Wang, A. Lozano-Leon et al., "Targeting ALDH ${ }^{\text {b- }}$ right human carcinoma-initiating cells with ALDH1A1specific CD8 ${ }^{+}$T cells," Clinical Cancer Research, vol. 17, no. 19, pp. 6174-6184, 2011.

[204] L. Jin, K. J. Hope, Q. Zhai, F. Smadja-Joffe, and J. E. Dick, "Targeting of CD44 eradicates human acute myeloid leukemic stem cells," Nature Medicine, vol. 12, no. 10, pp. 11671174, 2006.

[205] Y. Guo, J. Ma, J. Wang et al., "Inhibition of human melanoma growth and metastasis in vivo by anti-CD44 monoclonal antibody," Cancer Research, vol. 54, no. 6, pp. 1561-1565, 1994.

[206] S. K. Swaminathan, M. R. Olin, C. L. Forster, K. S. S. Cruz, J. Panyam, and J. R. Ohlfest, "Identification of a novel monoclonal antibody recognizing CD133," Journal of Immunological Methods, vol. 361, no. 1-2, pp. 110-115, 2010.

[207] F. Ferrari, S. Bellone, J. Black et al., "Solitomab, an EpCAM/ $\mathrm{CD} 3$ bispecific antibody construct $\left(\mathrm{BiTE}^{\circledR}\right)$, is highly active against primary uterine and ovarian carcinosarcoma cell lines in vitro," Journal of Experimental \& Clinical Cancer Research, vol. 34, no. 1, p. 123, 2015.

[208] M. Sen, D. M. Wankowski, N. K. Garlie et al., "Use of antiCD3 $\times$ anti-HER2/neu bispecific antibody for redirecting cytotoxicity of activated T cells toward HER $2 /$ neu $^{+}$tumors," Journal of Hematotherapy \& Stem Cell Research, vol. 10, no. 2, pp. 247-260, 2001.

[209] F. Dammeijer, L. A. Lievense, M. E. Kaijen-Lambers et al., "Depletion of tumor-associated macrophages with a CSF$1 \mathrm{R}$ kinase inhibitor enhances antitumor immunity and survival induced by DC immunotherapy," Cancer Immunology Research, vol. 5, no. 7, pp. 535-546, 2017.

[210] D. R. Yang, X. F. Ding, J. Luo et al., "Increased chemosensitivity via targeting testicular nuclear receptor 4 (TR4)-Oct4interleukin 1 receptor antagonist (IL1Ra) axis in prostate cancer $\mathrm{CD}_{133^{+}}$stem/progenitor cells to battle prostate cancer," Journal of Biological Chemistry, vol. 288, no. 23, pp. 16476-16483, 2013.

[211] S. Y. Kim, J. W. Kang, X. Song et al., "Role of the IL-6-JAK1STAT3-Oct-4 pathway in the conversion of non-stem cancer cells into cancer stem-like cells," Cellular Signalling, vol. 25, no. 4, pp. 961-969, 2013.

[212] C. Ginestier, S. Liu, M. E. Diebel et al., "CXCR1 blockade selectively targets human breast cancer stem cells in vitro and in xenografts," The Journal of Clinical Investigation, vol. 120, no. 2, pp. 485-497, 2010.

[213] S. L. Topalian, F. S. Hodi, J. R. Brahmer et al., "Safety, activity, and immune correlates of anti-PD-1 antibody in cancer," The New England Journal of Medicine, vol. 366, no. 26, pp. 2443-2454, 2012.

[214] S. M. Ansell, A. M. Lesokhin, I. Borrello et al., "PD-1 blockade with nivolumab in relapsed or refractory Hodgkin's 
lymphoma," The New England Journal of Medicine, vol. 372, no. 4, pp. 311-319, 2015.

[215] Y. Hu and L. Fu, "Targeting cancer stem cells: a new therapy to cure cancer patients," American Journal of Cancer Research, vol. 2, no. 3, pp. 340-356, 2012.

[216] S. R. Pine, B. Marshall, and L. Varticovski, "Lung cancer stem cells,” Disease Markers, vol. 24, no. 4-5, pp. 257-266, 2008.

[217] T. Chanmee, P. Ontong, K. Kimata, and N. Itano, "Key roles of hyaluronan and its CD44 receptor in the stemness and survival of cancer stem cells," Frontiers in Oncology, vol. 5, 2015.

[218] Y. J. Kim, E. L. Siegler, N. Siriwon, and P. Wang, "Therapeutic strategies for targeting cancer stem cells," Journal of Cancer Metastasis and Treatment, vol. 2, no. 7, pp. 233-242, 2016.

[219] D. L. Dragu, L. G. Necula, C. Bleotu, C. C. Diaconu, and M. Chivu-Economescu, "Therapies targeting cancer stem cells: current trends and future challenges," World Journal of Stem Cells, vol. 7, no. 9, pp. 1185-1201, 2015.

[220] L. Han, S. Shi, T. Gong, Z. Zhang, and X. Sun, "Cancer stem cells: therapeutic implications and perspectives in cancer therapy," Acta Pharmaceutica Sinica B, vol. 3, no. 2, pp. 65-75, 2013.

[221] C. Zhang, C. Li, F. He, Y. Cai, and H. Yang, "Identification of CD44+CD24+ gastric cancer stem cells," Journal of Cancer Research and Clinical Oncology, vol. 137, no. 11, pp. 1679-1686, 2011.

[222] S. Takaishi, T. Okumura, S. Tu et al., "Identification of gastric cancer stem cells using the cell surface marker CD44," Stem Cells, vol. 27, no. 5, pp. 1006-1020, 2009.

[223] A. T. Collins, P. A. Berry, C. Hyde, M. J. Stower, and N. J. Maitland, "Prospective identification of tumorigenic prostate cancer stem cells," Cancer Research, vol. 65, no. 23, pp. 10946-10951, 2005.

[224] M. J. Son, K. Woolard, D. H. Nam, J. Lee, and H. A. Fine, "SSEA-1 is an enrichment marker for tumor-initiating cells in human glioblastoma," Cell Stem Cell, vol. 4, no. 5, pp. 440-452, 2009.

[225] M. E. Prince, R. Sivanandan, A. Kaczorowski et al., "Identification of a subpopulation of cells with cancer stem cell properties in head and neck squamous cell carcinoma," Proceedings of the National Academy of Sciences of the United States of America, vol. 104, no. 3, pp. 973-978, 2007.

[226] S. K. Singh, C. Hawkins, I. D. Clarke et al., "Identification of human brain tumour initiating cells," Nature, vol. 432, no. 7015, pp. 396-401, 2004. 


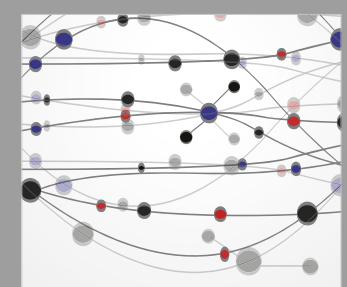

The Scientific World Journal
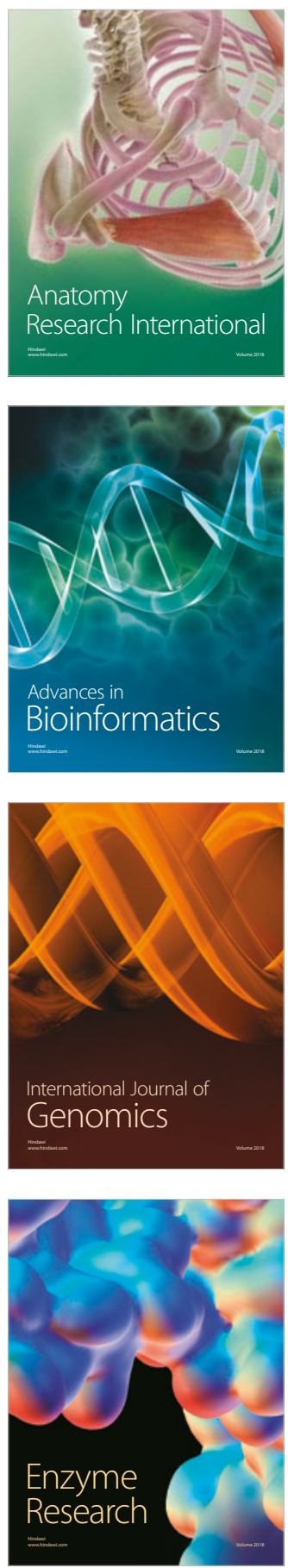
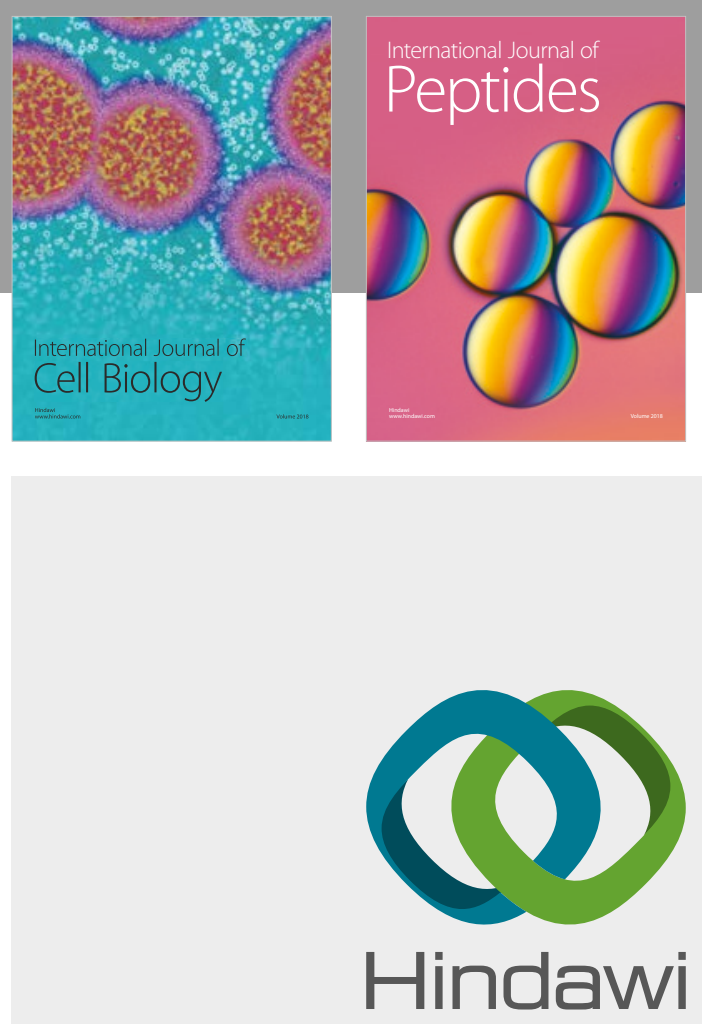

Submit your manuscripts at

www.hindawi.com
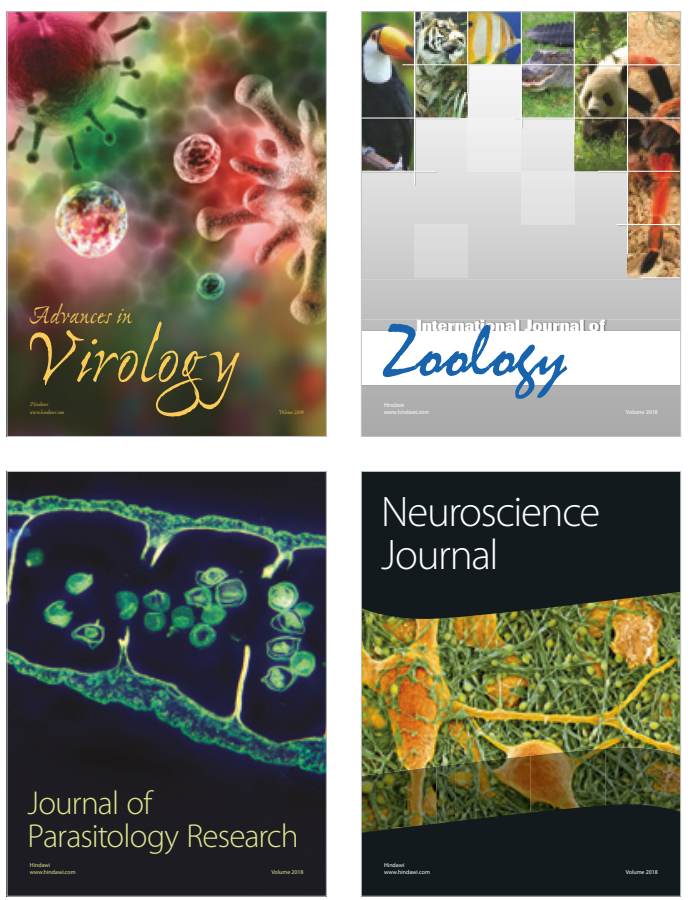
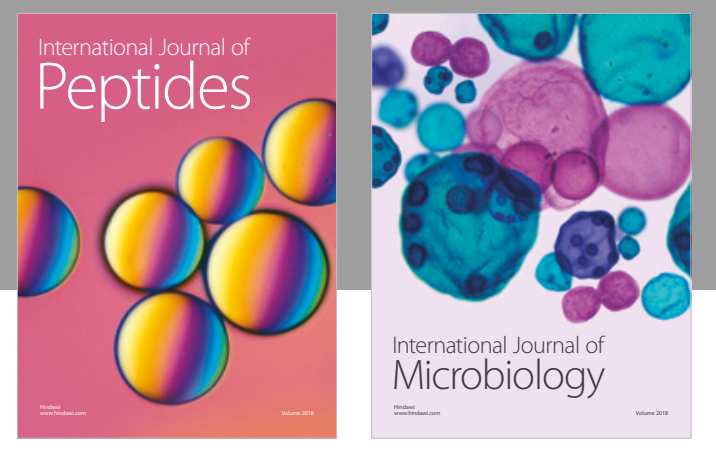

nternational Journal of Microbiology
Journal of
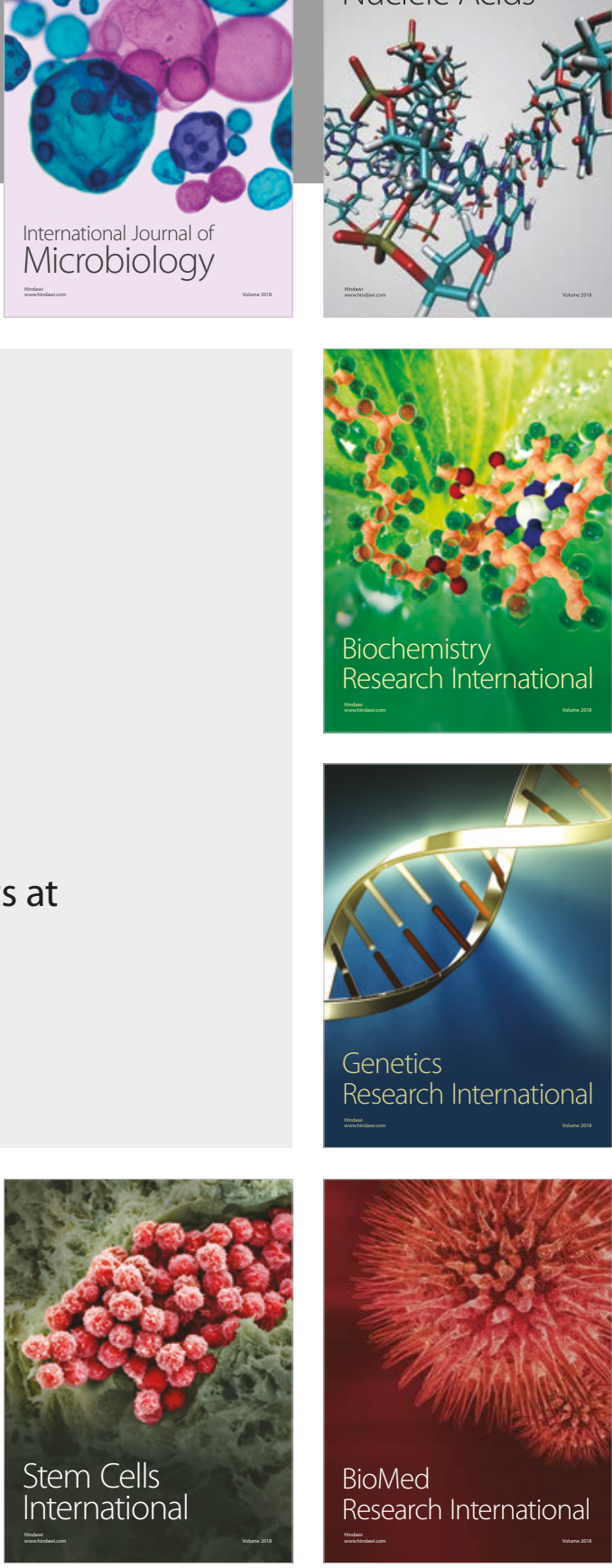
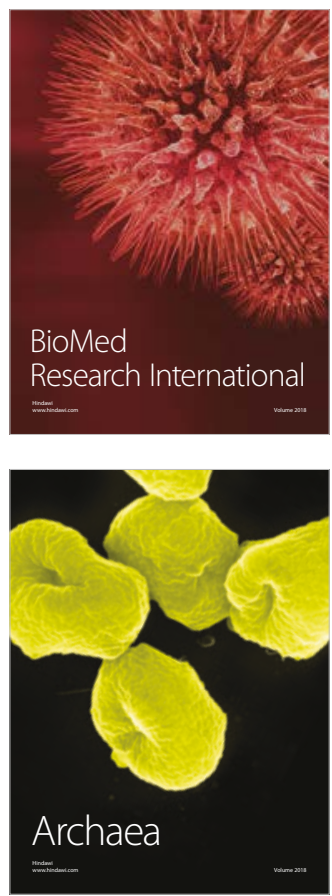